\title{
Combined resistance to oxidative stress and reduced antenna size enhance light-to-biomass conversion efficiency in Chlorella vulgaris cultures
}

\author{
Luca Dall'Osto $^{1 \dagger}{ }^{\mathbb{D}}$, Stefano Cazzaniga ${ }^{1 \dagger}$, Zeno Guardini $^{1}$, Simo Barera ${ }^{1}$, Manuel Benedetti ${ }^{1}$,
} Giuseppe Mannino ${ }^{2}$, Massimo E. Maffei ${ }^{2}$ and Roberto Bassi ${ }^{1^{*}}$

\begin{abstract}
Background: Microalgae are efficient producers of lipid-rich biomass, making them a key component in developing a sustainable energy source, and an alternative to fossil fuels. Chlorella species are of special interest because of their fast growth rate in photobioreactors. However, biological constraints still cast a significant gap between the high cost of biofuel and cheap oil, thus hampering perspective of producing $\mathrm{CO}_{2}$-neutral biofuels. A key issue is the inefficient use of light caused by its uneven distribution in the culture that generates photoinhibition of the surface-exposed cells and darkening of the inner layers. Efficient biofuel production, thus, requires domestication, including traits which reduce optical density of cultures and enhance photoprotection.
\end{abstract}

Results: We applied two steps of mutagenesis and phenotypic selection to the microalga Chlorella vulgaris. First, a pale-green mutant ( $P$ G-14) was selected, with a $50 \%$ reduction of both chlorophyll content per cell and LHCIl complement per PSII, with respect to WT. PG-14 showed a 30\% increased photon conversion into biomass efficiency vs. WT. A second step of mutagenesis of $P G-14$, followed by selection for higher tolerance to Rose Bengal, led to the isolation of pale-green genotypes, exhibiting higher resistance to singlet oxygen (strains SOR). Growth in photobioreactors under high light conditions showed an enhanced biomass production of SOR strains with respect to $P G-14$. When compared to WT strain, biomass yield of the pale green + sor genotype was enhanced by $68 \%$.

Conclusions: Domestication of microalgae like Chlorella vulgaris, by optimizing both light distribution and ROS resistance, yielded an enhanced carbon assimilation rate in photobioreactor.

Keywords: Microalgae, Chloroplast, Biofuel, Excess light, Photoprotection, Singlet oxygen, Biomass

\section{Background}

The rapid burning of fossil fuels impacts on Earth's climate making the search for carbon-neutral fuels solutions urgent. Liquid fuels derived from photosynthetic

\footnotetext{
*Correspondence: roberto.bassi@univr.it

†Luca Dall'Osto and Stefano Cazzaniga contributed equally to this work 1 Dipartimento di Biotecnologie, Università di Verona, Strada Le Grazie 15, 37134 Verona, Italy

Full list of author information is available at the end of the article
}

organisms represent a renewable alternative to fossil fuels and a source of sustainable energy $[1,2]$. Mass cultures of microalgae in photobioreactors (PBRs) are a promising source of biomass for biofuel production on a large scale, due to the high productivity and lipid content, far exceeding the best crops [3-5]. In both microalgae and land plants, photosynthetic reactions are carried out by membrane supercomplexes and soluble enzymes [6]; yet, due to a simpler cellular structure, microalgae are far more efficient in converting solar energy into biomass. Moreover, when growing on marginal lands, algae do not compete with food crops for arable soils and a number 
of species can accumulate high level of lipids, up to over $50 \%$ of their dry biomass [7]. After oil extraction, the residual lipid-free biomass can be used as bio-stimulant and fertilizer or fermented to produce biogas [8]. Microalgae are also useful for wastewater bioremediation and $\mathrm{CO}_{2}$ mitigation because of their high capacity to recover nitrogen, phosphorus and heavy metals from industrial, municipal and agriculture wastes $[9,10]$.

Among microalgae species, members of the genus Chlorella gained importance as robust biomass accumulating strains, allowing for sustainable industrial productions of high-value products and biofuels [11]. Under high irradiance or nutrient (N, P) deficiency, Chlorella mass cultures increase their neutral lipid content [12] in the form of triacylglycerols, which serve as cellular storage molecules, thus making these organisms promising candidates for lipid-based biofuels production. Potential coupling of oil production with either wastewater bioremediation or $\mathrm{CO}_{2}$ abatement technologies to industrial applications may decrease the cost of biofuel production as well as provide significant environmental benefits [10].

Production of biofuels from microalgae, however, still suffers from limitations, hampering cost effectiveness. These include the costs for PBRs construction and management, water pumping and mixing, axenic practices for preventing contamination of monocultures, harvesting biomass and lipid extraction [5]. In addition, there are physiological limitations such as low efficiency of light use, especially under high irradiance. The maximal theoretical efficiency of photosynthetically active radiation (400-700 nm) (PAR) solar energy conversion into biomass is about 27\% [13]. However, such values are only observed at low light intensity in laboratory-scale growth trials, while efficiency drops below $6 \%$ in outdoor cultures at full sunlight intensities [12]. Limits in biomass yield can be ascribed to a number of factors [14], including (i) light-saturation effect, (ii) inhomogeneous light distribution within a mass culture and (iii) photoinhibition.

The light-saturation effect becomes evident when considering the light response curves for photosynthesis compared with the rate of light absorption [15]. In low-light conditions, photosynthetic rates increase with increasing irradiance, and the rate of photon absorption is correlated with that of electron transport from water to $\mathrm{CO}_{2}$; at higher irradiance, the photosynthetic rate increases non-linearly with respect to light intensity, reaching light saturation $\left(P_{\max }\right)$. Within saturation range, excess energy is dissipated into heat. At even higher fluency, net assimilation decreases due to oxidative photoinhibition.

Within the light limited range, energy is efficiently used for photosynthesis. When light irradiance overcomes the rate of downstream biochemical reactions, excess absorbed energy is wasted as heat, thus impairing lightto-biomass conversion efficiency [16]. Additional energy loss derives from the inhomogeneous light distribution in the algal culture. The high optical density of algal cells at the surface causes a steep light gradient which leaves inner layers below compensation point with respiration causing energy loss. The high Chl content per cell maximizes the photon capture in the natural environment, with limiting light and low cell density. To this aim, large arrays of antenna complexes (Light-harvesting complexes, LHCs), binding chlorophylls (Chl) and carotenoid (Car) in quasi-molar concentration, enhance exciton supply to reaction centers, hosting photochemical reactions [17]. However, large antenna systems do not enhance overall productivity in a PBR because the high optical density readily leads to saturation of photosynthesis in the surface layers, while the inner space becomes light limited. The resulting inhomogeneous light distribution impairs productivity [18]. Upon sustained over-excitation experienced by cells of surface layers, increase in lifetime of $\mathrm{Chl}$ singlet excited states $\left({ }^{1} \mathrm{Chl}{ }^{*}\right)$ and intersystem crossing to the Chl triplet state $\left({ }^{3} \mathrm{Chl}{ }^{*}\right)$ occur. Moreover, reaction with molecular oxygen $\left(\mathrm{O}_{2}\right)$ yields singlet oxygen $\left({ }^{1} \mathrm{O}_{2}\right)$ hence photoinhibition of PSII, a complex highly susceptible to light damage $[19,20]$. Algal cells rapidly shift between layers with low vs. high irradiance due to mixing, which impairs the light acclimation capacity of their photosynthetic apparatus.

Domesticating microalgae for enhanced growth rate in PBRs requires introduction of traits alleviating these physiological constraints to (i) optimize the optical density per biomass unit and, (ii) increase the resistance to photo-oxidation [5]. Decreasing overall absorption of photosynthetic active radiation (PAR) per cell [21] improves light distribution in PBR so that cells facing the surface absorb less photons, while those in inner layers become net contributors to carbon fixation [22]. Increasing resistance to photo-oxidative damage is expected to decrease photoinhibition. Indeed, preventing photoinhibition was reported to increase fitness [23] and provide carbon gain [24]. However, it is unclear whether manipulation of photoprotection traits might have beneficial effects for mass culture in PBR environment once weighted against the metabolic cost these processes have in algae. In this work, we report on the construction of Chlorella vulgaris strains combining enhanced light transmittance and resistance to oxidative stress by two steps of mutagenesis followed by phenotypic selection. The first selection round yielded the pale-green PG14 strain with increased photon use efficiency and higher biomass productivity in PBR. Further mutagenesis/selection allowed to select pale-green strains with increased tolerance to ${ }^{1} \mathrm{O}_{2}$ (SOR strains). Selected SOR strains in 
PBR under strong irradiances showed further enhancement in productivity with respect to PG-14. Overall, these results show that resistance to oxidative stress is an important component of algal productivity. In addition, the traits responsible to improved optical properties can be combined with those providing oxidative stress resistance for the construction of domesticated algal strains with improved biomass yield for growth in PBRs.

\section{Results}

\section{Isolation of PG-14, a pale-green mutant of Chlorella} vulgaris

Chlorella vulgaris mutants that exhibited a pale-green $(P G)$ phenotype with respect to WT were visually screened following EMS mutagenesis (Additional file 1: Figure S1A, B). Approximately 25,000 mutagenized lines were visual screened, and seven independent mutants were identified as putatively affected in Chl content per cell. All these mutants were capable of phototrophic growth and displayed different levels of depletion in Chl (Additional file 1: Figure S1C). Among the identified strains, p1-14 showed the highest growth rate in batch conditions (Additional file 1: Figure S2). It was, therefore, selected for further analysis and renamed as PG-14.

Pigment composition of both mutant and WT strains was determined after 5 days of growth, as shown in Table 1. PG-14 showed a significant reduction of Chl content per cell $(-50 \%)$ when grown in minimal medium. The $\mathrm{Chl} a / b$ ratio was significantly higher in the mutant, with a value of 4.12 vs. 2.67 in WT, whereas the Chl/Car ratio was significantly lower in $P G-14$ (2.25) with respect to the WT (4.03). These data suggest a depletion in the Chl $b$-rich antenna complexes (LHC) in PG-14.

\section{Stoichiometry of pigment-protein complexes and photosynthetic electron transport}

To determine whether the capacity of the antenna system to transfer absorbed energy to RCs was affected by the mutation, Chl fluorescence analysis was used to quantify the PSII operating efficiency. No significant differences were observed in $F_{\mathrm{v}} / F_{\mathrm{m}}$ between $P G-14$ and WT (Table 1), suggesting that the maximal quantum yield of PSII photochemistry was not impaired in the $p g$ mutant. Functional antenna size of PSII was measured on cell suspensions in the presence of DCMU, by estimating the rise time of Chl $a$ fluorescence (Fig. 1a). The $T_{2 / 3}$ of the Chl fluorescence rise is inversely related to the functional antenna size of PSII [25] and was reduced by $\sim 35 \%$ in PG-14 with respect to WT (Table 1).

These results were further confirmed through biochemical estimation of PSII antenna size. The level of selected thylakoid proteins was determined by immunetitration on thylakoids and expressed relative to WT once normalized to the PSII core complex (CP43) content (Fig. 1b). The LHCII abundance was reduced in the PG14 mutant to $\sim 61 \%$ with respect to the WT level, while the PSI/PSII ratio was the same in both genotypes.

To investigate the functional properties of the photosynthetic machinery of the PG-14 mutant, the lightsaturation curve of photosynthesis was measured in photo-autotrophically grown cells (Fig. 1c). The rate of $\mathrm{O}_{2}$ release was shown to increase as a function of irradiance within the range of light intensities between 0 and $1000 \mu \mathrm{mol}$ photons $\mathrm{m}^{-2} \mathrm{~s}^{-1}$. The increase was linear for both WT and PG-14 at irradiances below $150 \mu \mathrm{mol}$ photons $\mathrm{m}^{-2} \mathrm{~s}^{-1}$. The slope of the linear regressions of $\mathrm{O}_{2}$ yield vs. light intensity for WT and PG-14 was $0.84 \pm 0.21$ and $1.32 \pm 0.35$, respectively, implying that the quantum yield of photosynthesis was significantly higher in the mutant with respect to WT. The light intensity for half-saturation of photosynthesis was similar in the two strains, at approximately $100 \mu \mathrm{mol}$ photons $\mathrm{m}^{-2} \mathrm{~s}^{-1}$ (Table 2); irradiances higher than $1000 \mu \mathrm{mol}$ photons $\mathrm{m}^{-2} \mathrm{~s}^{-1}$ were saturating for the $\mathrm{O}_{2}$ production in both WT and the PG-14 mutant (Fig. 1c). In WT, the maximum rate of light-induced oxygen evolution $P_{\max }$ (photosynthesis net respiration) was reached at $2000 \mu \mathrm{mol}$ photons $\mathrm{m}^{-2} \mathrm{~s}^{-1}$ and was equal to $96 \pm 5 \mu \mathrm{mol} \mathrm{O}_{2} \mathrm{mg}$

Table 1 Pigment content, PSII maximum quantum yield $\left(F_{\mathrm{v}} / F_{\mathrm{m}}\right)$ and PSII functional antenna size of WT and mutants PG14 and SOR

\begin{tabular}{|c|c|c|c|c|c|}
\hline Genotype & Chl/cel I (pg) & Chl $a / b$ & Chl/Car & $F_{\mathrm{v}} / F_{\mathrm{m}}$ & $\begin{array}{l}\text { PSII antenna size } \\
\left(\mathrm{T}_{2 / 3}^{-1} 10^{3} \mathrm{~ms}^{-1}\right)\end{array}$ \\
\hline WT & $0.26 \pm 0.03^{a}$ & $2.67 \pm 0.22^{\mathrm{a}}$ & $4.03 \pm 0.22^{\mathrm{a}}$ & $0.67 \pm 0.03^{a}$ & $6.74 \pm 0.49^{a}$ \\
\hline PG-14 & $0.13 \pm 0.02^{b}$ & $4.12 \pm 0.30^{b}$ & $2.25 \pm 0.13^{b}$ & $0.69 \pm 0.05^{\mathrm{a}}$ & $4.40 \pm 0.27^{b}$ \\
\hline SOR-1 & $0.13 \pm 0.02^{b}$ & $4.12 \pm 0.20^{b}$ & $2.24 \pm 0.17^{b}$ & $0.67 \pm 0.03^{a}$ & $4.17 \pm 0.21^{b}$ \\
\hline SOR-5 & $0.11 \pm 0.03^{b}$ & $3.96 \pm 0.31^{b}$ & $2.24 \pm 0.05^{b}$ & $0.66 \pm 0.03^{a}$ & $4.37 \pm 0.23^{b}$ \\
\hline SOR-6 & $0.13 \pm 0.03^{b}$ & $4.20 \pm 0.12^{b}$ & $2.25 \pm 0.07^{b}$ & $0.66 \pm 0.05^{\mathrm{a}}$ & $4.29 \pm 0.30^{b}$ \\
\hline
\end{tabular}

Parameters were measured on dark-adapted cell suspension of WT, PG-14 and SOR strains, upon 7 days of photoautotrophic growth in BG-11 medium in low light conditions $\left(100 \mu \mathrm{mol}\right.$ photons $\left.\mathrm{m}^{-2} \mathrm{~s}^{-1}, 25^{\circ} \mathrm{C}\right)$. Data are expressed as mean $\pm \mathrm{SD}, n>4$. For each parameter measured, significantly different values among genotypes (ANOVA test, $p<0.05$ ) are marked with different letters 


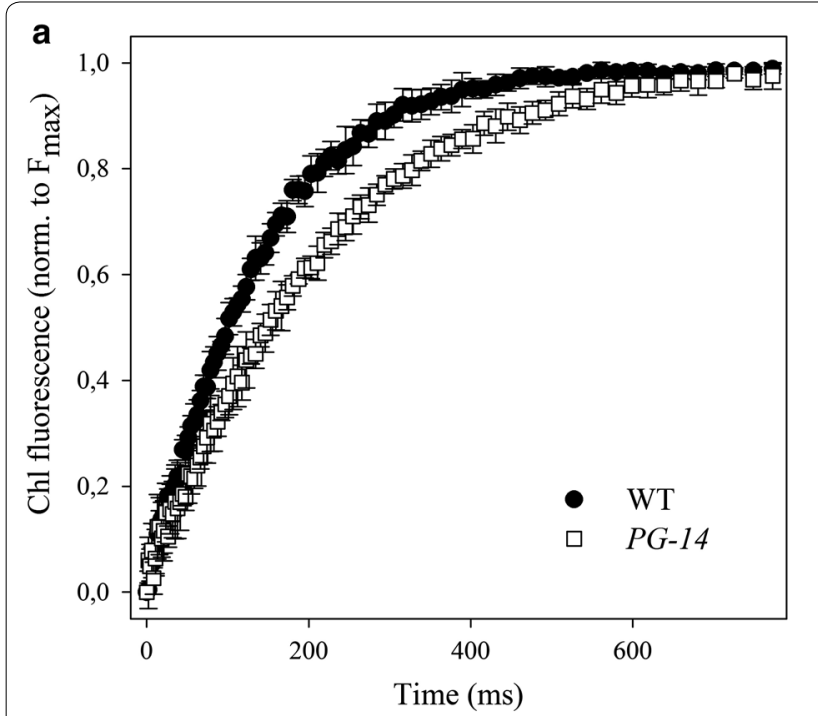

\section{b}
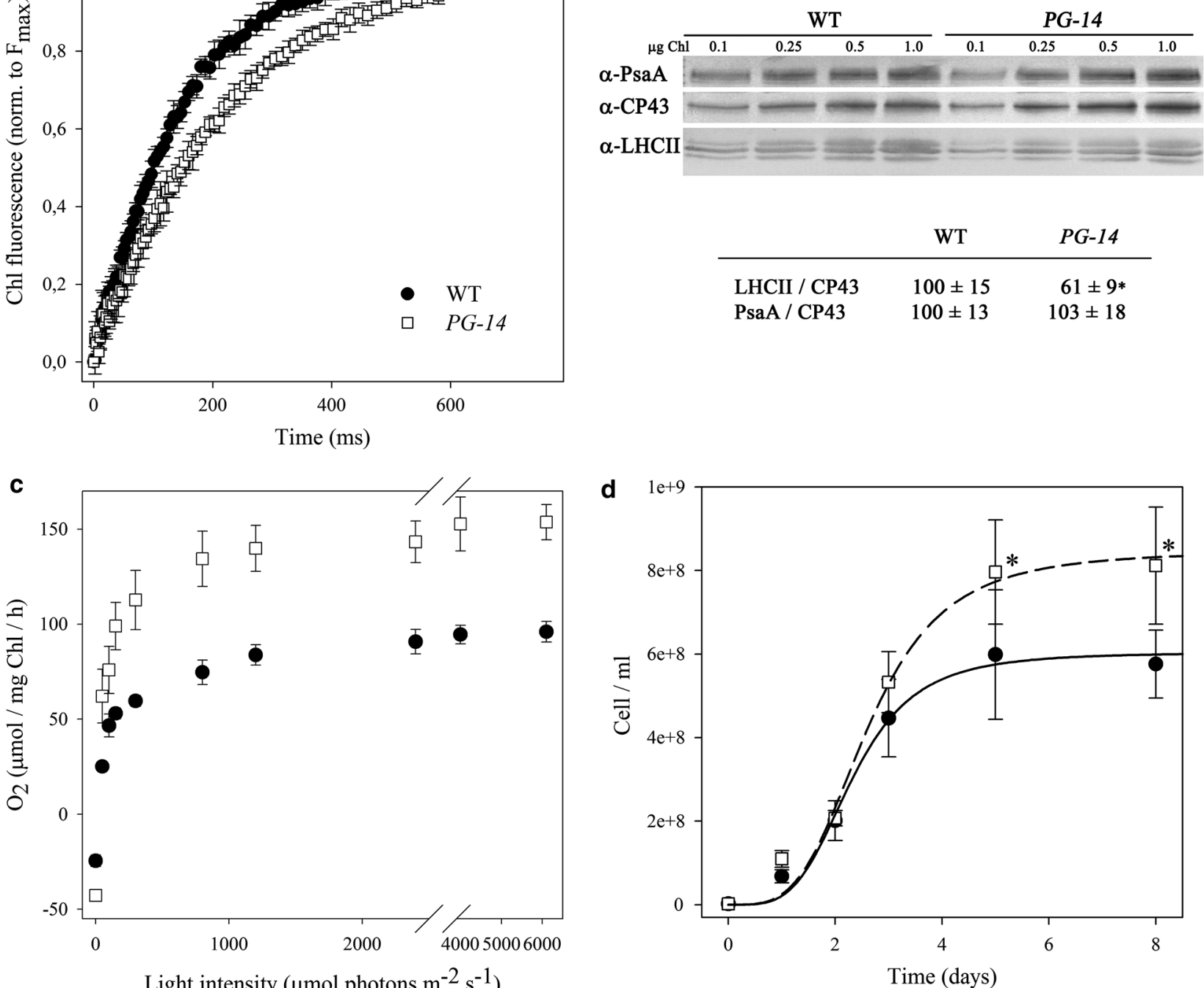

Light intensity ( $\mu \mathrm{mol}$ photons $\mathrm{m}^{-2} \mathrm{~s}^{-1}$ )

Fig. 1 Characterization of pale-green-14 (PG-14) mutant of Chlorella vulgaris. a PSIl functional antenna size. Variable Chl fluorescence was induced with a green light $\left(15 \mu \mathrm{mol}\right.$ photons $\left.\mathrm{m}^{-2} \mathrm{~s}^{-1}\right)$, on dark-adapted cells of WT and PG-14, in BG-11 medium supplemented with $50 \mu \mathrm{M}$ DCMU. Data are expressed as mean $\pm S D, n=10$. The reciprocal of time corresponding to two-thirds of the fluorescence rise $\left(T_{2 / 3}\right)$ was taken as a measure of the PSII functional antenna size (see Table 1). b Immunoblotting used for the quantification of photosynthetic subunits. Immunotitration was performed with antibodies directed against individual gene products: LHCII, the major light harvesting complex of PSIl; the PSII core subunit PsbC (CP43); the PSI core subunit (PsaA). The amount of Chls loaded for each lane is shown. Values significantly different (Student's $t$ test, $p<0.05$ ) with respect to the WT are marked with asterisks. $\mathbf{c}$ Light-saturation curves of photosynthesis. Measured cultures (panels $\mathbf{a}-\mathbf{c}$ ) were grown in minimal BG-11 medium at $100 \mu \mathrm{mol}$ photons $\mathrm{m}^{-2} \mathrm{~s}^{-1}$, in shaken flasks (120 rpm) illuminated from the top, photoperiod of 16/8 h light/dark, $25^{\circ} \mathrm{C}$. d Growth curves of wild type and PG-14 mutant under autotrophic conditions. All experiments were performed in 1-L cylinders, illuminated with $1400 \mu \mathrm{mol}$ photons $\mathrm{m}^{-2}$ $\mathrm{s}^{-1}, 25^{\circ} \mathrm{C}$. Growths were performed in a semi-batch system fed with air/ $\mathrm{CO}_{2} \mathrm{mix}$; the $\mathrm{CO}_{2}$ supply was modulated to keep the $\mathrm{pH}$ of the medium always below 7.1. Data are expressed as mean $\pm \mathrm{SD}, n=4$

$\mathrm{Chl}^{-1} \mathrm{~h}^{-1}$. PG-14 cells showed a significantly higher $P_{\max }$, i.e. (155 \pm 11$)$ (Table 2). Owing to the normalization of $\mathrm{O}_{2}$ production rate on Chl content, $P_{\max }$ is a measure of the Chl productivity for the two strains. The dark respiration rate was $25 \pm 3 \mu \mathrm{mol} \mathrm{O} \mathrm{mg} \mathrm{Chl}^{-1} \mathrm{~h}^{-1}$ in the WT vs. $43 \pm 3$ in PG-14 (Table 2), while it was the same in WT and mutant on a per cell basis. Altogether, these results imply that the PG-14 mutant possesses an enhanced photosynthetic productivity with respect to the WT. To verify this hypothesis, growth rate and biomass productivity analysis were performed. Photoautotrophic growth was monitored over a period of 8 days in a lab-scale 
Table 2 Photosynthesis and respiration rates

\begin{tabular}{|c|c|c|c|c|c|}
\hline Parameters & WT & PG-14 & SOR-1 & SOR-5 & SOR-6 \\
\hline Half-saturation intensity ( $\mu \mathrm{mol}$ photons $\mathrm{m}^{-2} \mathrm{~s}^{-1}$ ) & $110 \pm 24^{\mathrm{a}}$ & $96 \pm 41^{a}$ & $128 \pm 6^{\mathrm{a}}$ & $124 \pm 9^{a}$ & $118 \pm 29^{a}$ \\
\hline$P_{\max }\left(\mu \mathrm{mol} O 2 \mathrm{mg} \mathrm{Chl}^{-1} \mathrm{~h}^{-1}\right)$ & $96 \pm 5^{a}$ & $155 \pm 11^{b}$ & $146 \pm 8^{b}$ & $143 \pm 7^{b}$ & $150 \pm 3^{b}$ \\
\hline Respiration ( $\mu \mathrm{mol} \mathrm{O} 2 \mathrm{mg} \mathrm{Ch}^{-1} \mathrm{~h}^{-1}$ ) & $25 \pm 3^{a}$ & $43 \pm 3^{b}$ & $40 \pm 5^{b}$ & $47 \pm 7^{b}$ & $42 \pm 6^{b}$ \\
\hline Respiration (fmol oxygen cell ${ }^{-1} \mathrm{~h}^{-1}$ ) & $6.4 \pm 0.8^{\mathrm{a}}$ & $5.5 \pm 0.4^{\mathrm{a}}$ & $5.2 \pm 0.6^{\mathrm{a}}$ & $5.6 \pm 0.8^{\mathrm{a}}$ & $5.4 \pm 0.8^{\mathrm{a}}$ \\
\hline$P_{\max } /$ respiration (relative units) & $3.9 \pm 0.4^{\mathrm{a}}$ & $3.6 \pm 0.2^{\mathrm{a}}$ & $3.7 \pm 0.6^{\mathrm{a}}$ & $3.1 \pm 0.5^{\mathrm{a}}$ & $3.6 \pm 0.5^{a}$ \\
\hline
\end{tabular}

Parameters were measured on dark-adapted cell suspension of WT, PG-14 and SOR strains, upon 7 days of photoautotrophic growth in BG-11 medium in low light conditions $\left(100 \mu \mathrm{mol}\right.$ photons $\left.\mathrm{m}^{-2} \mathrm{~s}^{-1}, 25^{\circ} \mathrm{C}\right) . \mathrm{O}_{2}$ evolution/consumption was measured with a Clark-type oxygen electrode (Oxygraph, Hansatech). Data are expressed as mean \pm SD $(n>4)$. For each parameter measured, significantly different values among genotypes (ANOVA test, $p<0.05)$ are marked with different letters

photobioreactor, a semi-batch cultivation system composed of 1-L glass cylinders exposed at a light intensity of $1400 \mu \mathrm{mol}$ photons $\mathrm{m}^{-2} \mathrm{~s}^{-1}$. The system was fed with a flux of air and $\mathrm{CO}_{2}$, whose relative abundance was regulated by the $\mathrm{pH}$ of the medium in order to keep it within the range 6.8-7.2. The PG-14 culture reached a cell concentration of $\sim 8.1 \cdot 10^{8}$ cell $\mathrm{mL}^{-1}$ at day five vs. $6.0 \cdot 10^{8}$ cell $\mathrm{mL}^{-1}$ obtained in the WT (Fig. 1d), with a specific growth rate $(\mu)$ of the mutant which was significantly higher than the WT $\left(2.00\right.$ day $^{-1}$ for PG-14 and 1.87 day $^{-1}$ for WT, Table 3). Moreover, the mutant showed a higher mean biomass productivity, equal to $550 \mathrm{mg} \mathrm{L}^{-1}$ day $^{-1}$, which was significantly higher $(+28 \%)$ with respect to that in the corresponding WT (Table 3).

\section{Isolation of pale-green, singlet oxygen-resistant strains} When experiencing excess light (EL) conditions, microalgae activate acclimatory responses involving induction of genes encoding products conferring enhanced tolerance to ${ }^{1} \mathrm{O}_{2}$ stress [15].

To identify mutants with constitutively activated acclimation, we performed a screening for lines showing an increased tolerance to exogenous ${ }^{1} \mathrm{O}_{2}$. The PG-14 strain was mutagenized by EMS and plated onto agar containing the ${ }^{1} \mathrm{O}_{2}$-photosensitizer Red Bengal (RB) used at the minimal concentration $(12 \mu \mathrm{M})$ needed to inhibit growth of WT cells. Plates were exposed to a light-dark cycle $(16: 8 \mathrm{~h})$ for 10 days, at which point 18 RB-resistant clones were isolated. To verify increased ${ }^{1} \mathrm{O}_{2}$ resistance, colonies were picked to liquid medium in microtiter plates, and then re-evaluated for ${ }^{1} \mathrm{O}_{2}$ tolerance by spotting cells in agar plates containing $12 \mu \mathrm{M}$ RB (Fig. 2a). The three clones which passed the second screen were named as singlet oxygen resistant (SOR) mutants. No significant difference in the growth rates with respect to the parental line PG-14 on control agar conditions were observed with these three mutant strains (Fig. 2a). RB significantly impaired growth of all genotypes; however, the effect was far more severe in the PG-14 strains with respect to $S O R$ mutants. The ${ }^{1} \mathrm{O}_{2}$ resistance of the three $S O R$ clones was quantified (Fig. 2b): cultures of SOR-1, -5 and -6 and the parental strain PG-14 were exposed to increasing concentrations of $\mathrm{RB}(0-50 \mu \mathrm{M})$ in liquid cultures for $24 \mathrm{~h}$, upon which, cells were spotted on agar plates. All SOR strains showed higher survival rates at high RB concentrations $(\geq 25 \mu \mathrm{M})$ with respect to the parental strain.

Table 3 Growth parameters of WT, PG-14 and SOR strains, cultured in air/CO $\mathrm{CO}_{2}$ bubbling system

\begin{tabular}{|c|c|c|c|c|}
\hline \multirow[t]{3}{*}{ Genotype } & \multicolumn{4}{|l|}{ Lab-scale, indoor PBR } \\
\hline & \multicolumn{2}{|l|}{$1400 \mu \mathrm{mol}$ photons $\mathrm{m}^{-2} \mathrm{~s}^{-1}$} & \multicolumn{2}{|l|}{$50 \mu \mathrm{mol}$ photons $\mathrm{m}^{-2} \mathrm{~s}^{-1}$} \\
\hline & $\begin{array}{l}\text { Mean increase of biomass } \\
\left(\mathrm{g} \mathrm{I}^{-1} \mathrm{day}^{-1}\right)\end{array}$ & $\mu\left(\right.$ day $\left.^{-1}\right)$ & $\begin{array}{l}\text { Mean increase of biomass } \\
\left(\mathrm{g} \mathrm{I}^{-1} \text { day-1) }\right.\end{array}$ & $\mu\left(\right.$ day $\left.^{-1}\right)$ \\
\hline WT & $0.43 \pm 0.03^{\mathrm{a}}$ & $1.87 \pm 0.08^{\mathrm{a}}$ & $0.059 \pm 0.023^{a}$ & $0.94 \pm 0.09^{a}$ \\
\hline$P G-14$ & $0.55 \pm 0.02^{b}$ & $2.00 \pm 0.07^{b}$ & $0.024 \pm 0.004^{b}$ & $0.85 \pm 0.13^{\mathrm{a}}$ \\
\hline SOR-1 & $0.58 \pm 0.03^{b}$ & $1.97 \pm 0.04^{\mathrm{a}, \mathrm{b}}$ & $0.059 \pm 0.008 a$ & $0.94 \pm 0.08^{\mathrm{a}}$ \\
\hline SOR-5 & $0.70 \pm 0.03 c$ & $2.07 \pm 0.03 c$ & $0.048 \pm 0.002 c$ & $0.94 \pm 0.09^{a}$ \\
\hline SOR-6 & $0.72 \pm 0.04 c$ & $2.09 \pm 0.03 c$ & $0.049 \pm 0.015 c$ & $0.94 \pm 0.08^{a}$ \\
\hline
\end{tabular}

Biomass increase was measured by the determination of dry biomass accumulated after the cultivation period, divided by the number of days of cultivation (see Fig. 6). $\mu$, specific growth rate, was calculated from the slope of logarithmic cell concentration curve. Growth was performed under autotrophic conditions, in 1-L cylinders, illuminated with either 1400 or $50 \mu \mathrm{mol}$ photons $\mathrm{m}^{-2} \mathrm{~s}^{-1}, 25^{\circ} \mathrm{C}$. Data are expressed as mean $\pm \mathrm{SD}, n>3$. For each parameter and condition measured, significant different values among genotypes (ANOVA test, $p<0.05$ ) are marked with different letters 


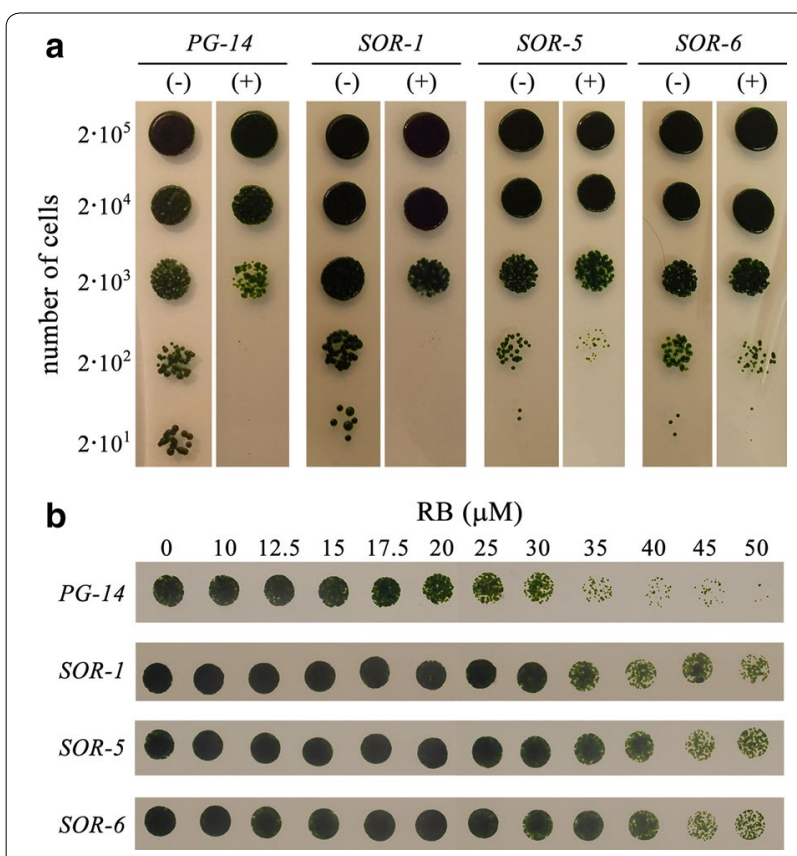

Fig. 2 Isolation of singlet-oxygen-resistant $(S O R)$ lines of $C$. vulgaris. a SOR-1, SOR-5 and SOR-6 strains were isolated as a ${ }^{1} \mathrm{O}_{2}$-resistant mutant by growing on solid TAP medium either containing (+) or not ( $(-)$ of Red Bengal (RB $12 \mu \mathrm{M})$. The amount of cells spotted is indicated in the left border. $\mathbf{b}$ Quantitative analyses of the resistance of SOR strains to oxidative stress. Cells were grown in liquid cultures with increasing concentration of RB $(0-50 \mu \mathrm{M})$ for $24 \mathrm{~h}$, then were spotted on

TAP-agar for recovery. Plates were illuminated with $100 \mu \mathrm{mol}$ photons $\mathrm{m}^{-2} \mathrm{~s}^{-1}$, photoperiod of 16-/8-h light/dark, $25^{\circ} \mathrm{C}$

PG-14 and SOR mutants showed the same phenotype as for the $\mathrm{Chl} /$ cell, $\mathrm{Chl} a / b$ and $\mathrm{Chl} / \mathrm{Car}$ ratios (Table 1 ), suggesting that the size of LHC antenna system was similar to the parental line PG-14. This was confirmed through immunotitration: both LHCII content and PSI/ PSII ratio of SOR mutants were the same as measured in PG-14 (Fig. 3a). No significant differences were observed in both PSII operating efficiency $\left(F_{\mathrm{v}} / F_{\mathrm{m}}\right)$ and functional antenna size of PSII, with respect to the corresponding parental line (Fig. 3b, Table 1). In both SOR and PG-14 strains, the light-saturation curves of photosynthesis (Fig. 3c) showed similar values for the maximum rate of light-induced oxygen evolution $\left(P_{\max }\right)$, half-saturation intensity for photosynthesis and dark respiration rates on a per cell basis (Table 2), thus indicating that the SOR mutant strains maintained the reduction in antenna size and the enhanced photosynthetic productivity previously shown in PG-14 cells.

\section{Sensitivity to photooxidative stress of SOR strains}

Under strong light, microalgae undergo photooxidative stress [15]. Under such conditions, enhanced release of
${ }^{1} \mathrm{O}_{2}$ leads to bleaching of pigments, lipid oxidation and a decrease of photosynthetic efficiency. Mechanisms evolved by photosynthetic organisms to limit photooxidative damage and acclimate to changes in the light environment include increasing Car pool size and a specific acclimation response enhancing ${ }^{1} \mathrm{O}_{2}$-resistance. Therefore, the mutant strains SOR, with a constitutive up-regulation of protective mechanisms are expected to better perform under photooxidative stress conditions, by limiting pigment-protein damage and ultimately, photoinhibition.

The sensitivity to EL stress of WT, PG-14 and SOR mutant strains was assessed upon transfer of cells from control conditions to $\mathrm{HL}$ at $25{ }^{\circ} \mathrm{C}$, then a time-course lipid peroxidation and pigment bleaching was measured (Fig. 4). When cells were exposed to $1400 \mu$ mol photons $\mathrm{m}^{-2} \mathrm{~s}^{-1}$ for $24 \mathrm{~h}$, malondialdehyde production was 1.5 times higher in both WT and PG-14 cells with respect to SOR (Fig. 4a) strains, implying a significantly lower level of lipid peroxidation in the latter.

We further examined liquid cultures of the WT and the mutants, at various times after transfer of low lightgrown cells to extremely high irradiances $(14,000 \mu \mathrm{mol}$ photons $\mathrm{m}^{-2} \mathrm{~s}^{-1}$, at $\left.25^{\circ} \mathrm{C}\right)$. In both WT and PG-14 cell suspensions, the $\mathrm{Chl}$ content decreased progressively upon exposure to HL until it reached $\sim 40 \%$ of the initial value, after 2-h treatment (Fig. 4b). The rate of $\mathrm{Chl}$ bleaching was three times faster in WT or PG-14 with respect to $S O R$ strains (Fig. 4b).

To assess whether the SOR mutations affect the composition of the photosynthetic machinery, we determined the accumulation level of selected chloroplast proteins relative to the WT by immunotitration in ELgrown cells (Additional file 1: Figure S3). LHCII content was reduced in all mutants, ranging between 45 and $60 \%$ with respect to WT on a Chl basis. On the other hand, the PSI: PSII ratio was similar in all genotypes. Cytochrome $f$ complex and ATP synthase ( $\beta$ subunits) were present in higher amounts in all mutants with respect to the WT. Rubisco was increased in all mutants $(\times 1.5-2$ with respect to the WT level $)$, with the only exception of SOR-1 strain, whose Rubisco content accounted to $70 \%$ of the control strain (Additional file 1: Figure S3).

The antioxidant properties of the algal biomass are related to the efficiency of the detoxification mechanisms. To assess the antioxidant capacity of the extracts from WT and mutant lines, we resorted to more than one method, since the activity of an extract depends on its composition, polarity of extraction solvents and type of assay used.

FRAP assay measures the capacity of an antioxidant in the reduction of the oxidant $\mathrm{Fe}^{3+}$ ion. When tested 


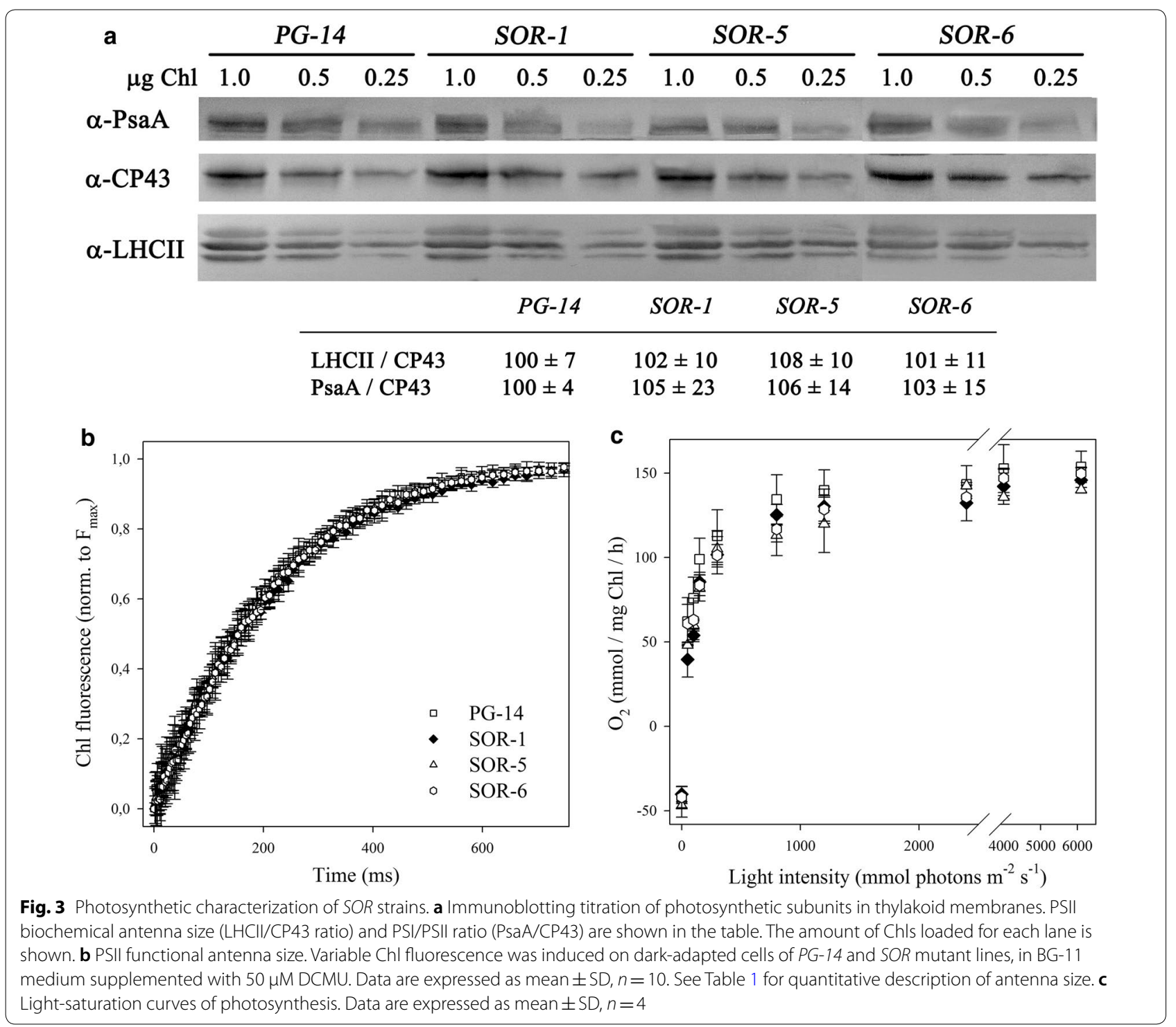

by FRAP, the levels of antioxidant activity of the different samples were as follows: $S O R \geq P G-14>$ WT (Fig. 5a). ABTS (2,2'-azino-bis(3-ethylbenzothiazoline-6-sulphonic acid) assay, which requires a buffered aqueous solution, yielded very high scavenging activity in PG-14 extracts; while all other mutants showed a significantly $(p<0.05)$ lower activity, even though far higher than the WT (Fig. 5b).

\section{Cultivation of WT and mutant strains in laboratory-scale photobioreactor}

The above results show that the mutant strains SOR have both enhanced efficiency of light energy conversion and higher tolerance to conditions of EL with respect to $P G$ 14 and WT strains, suggesting that they could have an enhanced light-to-biomass conversion yield. To verify such increased yield, growth rate and biomass productivity were further assessed in SOR lines. Photoautotrophic growth was monitored over a period of 6 days in the lab-scale $1 \mathrm{~L}$ PBR at $1400 \mathrm{uE}$. Both the SOR-5 and SOR- 6 cultures reached a cell concentration of about 6.8 $10^{8}$ cell $\mathrm{mL}^{-1}$ at day six vs. $5.110^{8}$ cell mL ${ }^{-1}$ in the $P G$ 14 (Fig. 6a), with a specific growth rate $(\mu)$ higher than for PG-14 (Table 3). Moreover, these mutants showed a higher mean biomass productivity, equal to $700 \mathrm{mg} \mathrm{L}^{-1}$ day $^{-1}$, that was significantly improved $(+30 \%)$ respect to the corresponding value for the PG-14 $\left(550 \mathrm{mg} \mathrm{L}^{-1}\right.$ $\mathrm{day}^{-1}$ ) and for WT (430 $\mathrm{mg} \mathrm{L}^{-1} \mathrm{day}^{-1}$ ) (Table 3). The SOR-1 mutant did display a faster growth rate (Fig. 6a); however, it did not show any significant enhancement in 

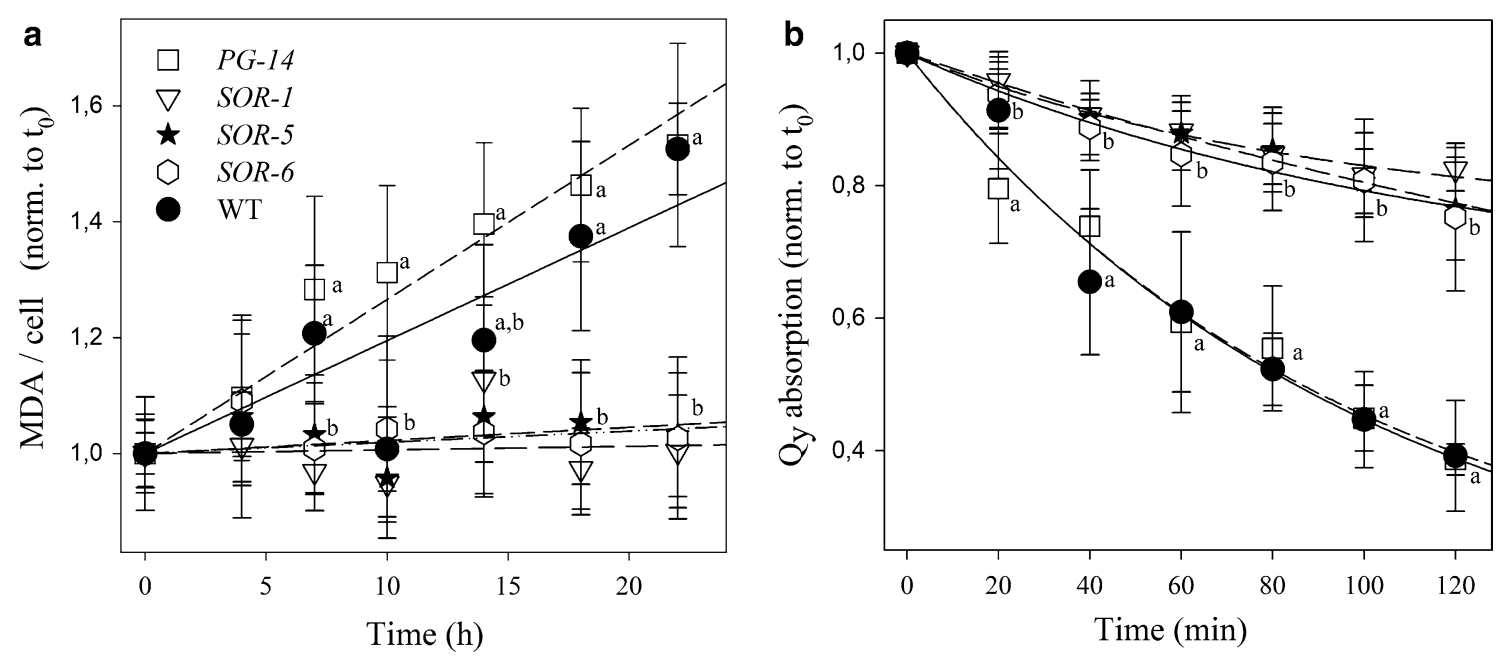

Fig. 4 Photooxidation of $C$. vulgaris WT, PG-14 and SOR mutant genotypes under photooxidative stress. a Cell suspensions were treated with $1400 \mu \mathrm{mol}$ photons $\mathrm{m}^{-2} \mathrm{~s}^{-1}$ at $20^{\circ} \mathrm{C}$, and kinetics of malondialdehyde (MDA) formation were followed. MDA is an index of membrane lipid peroxidation, and was quantified by HPLC as thiobarbituric reactive substances. (B) Cell suspension of WT and mutant strains were treated with strong white light $\left(14,000 \mu \mathrm{mol}\right.$ photons $\left.\mathrm{m}^{-2} \mathrm{~s}^{-1}, 20^{\circ} \mathrm{C}\right)$ and the amount of $\mathrm{Chl}$ was evaluated by measuring the absorption area in the region 600-750 nm. See "Materials and methods" for details. Symbols and error bars show mean $\pm S D, n=4$. Values marked with the same letters are not significantly different from each other within the same time point (ANOVA, $p<0.05$ )
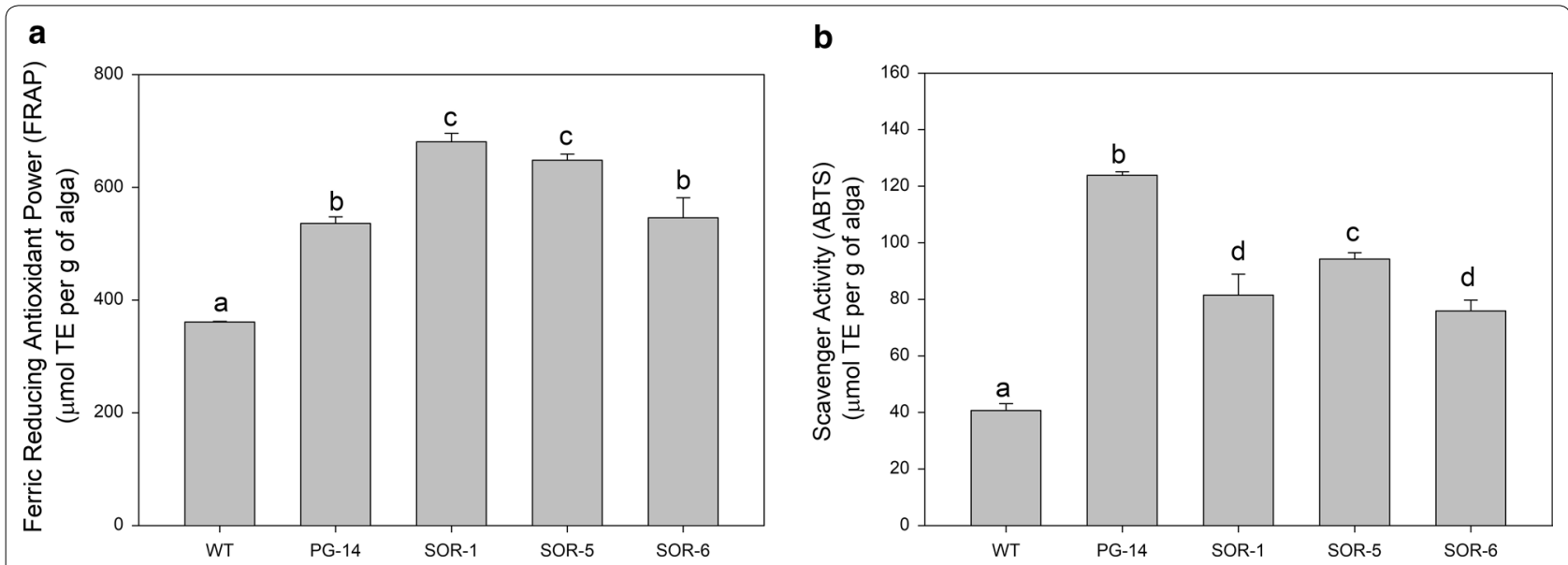

Fig. 5 Comparison of antioxidant activity of whole-cell extracts from C. vulgaris WT and mutants PG-14 and SOR. Antioxidant activity was measured by FRAP (a) and ABTS $(\mathbf{b})$ assays. Within each panel, different letters indicate significant (ANOVA test, $p<0.05$ ) differences. The values are the mean of 3 replicates, metric bars indicate SD

biomass productivity $\left(580 \mathrm{mg} \mathrm{L}^{-1}\right.$ day $\left.^{-1}\right)$ with respect to PG-14 (Table 3).

Among the mechanisms possibly underlying the higher biomass yield of SORs, the most relevant is the Non-Photochemical Quenching (NPQ), which catalyzes dissipation, as heat, of the light energy absorbed in excess. In WT, PG-14 and SOR genotypes, NPQ amplitude was measured at steady-state photosynthesis over a range of irradiances, showing differences mostly negligible (Fig. 7a). Moreover, recovery of $F_{\mathrm{v}} / F_{\mathrm{m}}$ upon photoinhibition (Fig. 7b) showed that all strains had the same behavior, implying that the higher growth of mutants was due to enhanced PSII repair.

The enhanced growth of the three SOR strain in HL is consistent with their truncated antenna system and resistance to ROS. However, it is unclear whether it is also due to enhanced efficiency in light-use efficiency. To explore this possibility, we grew these strains as well as WT and PG-14 in limiting-light conditions (Fig. 6b). At $50 \mu \mathrm{mol}$ photons $\mathrm{m}^{-2} \mathrm{~s}^{-1}$, PG-14 had a 

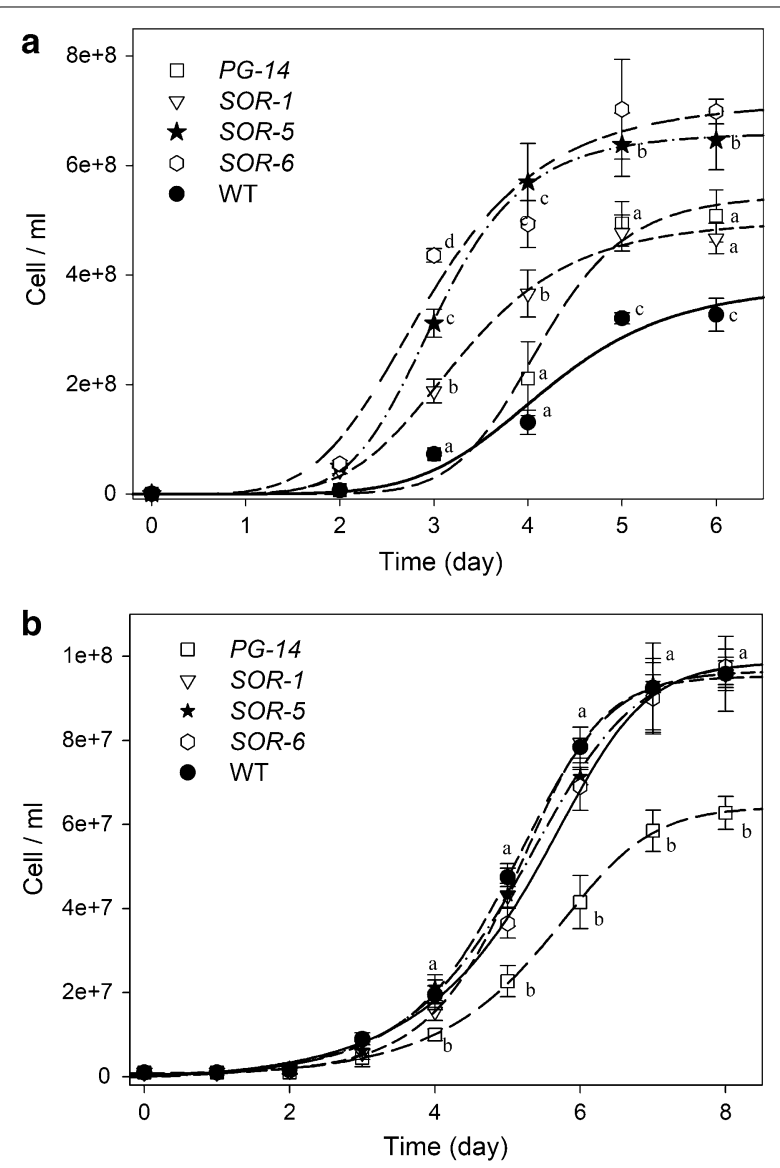

Fig. 6 Growth curves of WT and mutant strains. Growth of WT, PG-14 and SOR strains was performed under autotrophic conditions, at $25^{\circ} \mathrm{C}$, in 1-L cylinders, illuminated with either $1400 \mu \mathrm{mol}$ photons $\mathrm{m}^{-2} \mathrm{~s}^{-1}$ (panel a) or $50 \mu \mathrm{mol}$ photons $\mathrm{m}^{-2} \mathrm{~s}^{-1}$ (pane/ $\mathbf{b}$ ). Cultures were maintained in a semi-batch system fed with air/ $\mathrm{CO}_{2} \mathrm{mix} ; \mathrm{CO}_{2}$ supply was modulated in order to keep the $\mathrm{pH}$ of the medium always below 7.2. Symbols and error bars show mean $\pm S D, n \geq 6$. Values marked with the same letters are not significantly different from each other within the same time point (ANOVA, $p<0.05$ )

lower grow rate with respect to WT as expected from its reduced antenna size. The three SOR mutants had a growth kinetic and final biomass yield similar to WT, despite they had a reduced antenna size, similar to $P G$ 14 (Fig. 6b, Table 3). These results are consistent with enhanced growth rate of SOR mutants being caused not merely by enhanced ROS resistance plus enhanced growth penetration in the culture, but also by enhanced light-use efficiency in low light.

\section{Investigation of lipid production as a response to nitrogen starvation}

Lipid yield is a key parameter to be considered when aiming to produce biofuels. Stress factors, such as excess light [26, 27] and nitrogen starvation [28, 29], trigger lipid accumulation in algae. ROS likely participate as molecular mediators of stresses in algae as suggested by the correlation between lipid content and intracellular ROS level in C. vulgaris [30]. Because of this relation, the higher resistance to oxidative stress observed might prevent oil productivity by impairing ROS cross-talk signals. We, therefore, evaluated the lipid productivity in our selected mutants, under a two-stage cultivation protocol, in which microalgae were first grown in the standard BG-11 medium to achieve high cell density and then transferred to a modified BG-11 medium with limiting $\mathrm{N}$ source. At the end of growth phase, oil content per DW was determined gravimetrically. Dry biomass from WT contained $\sim 25 \%$ oil, in accordance with previous quantification in the same species [12]; $\mathrm{N}$-deprivation brought about oil content of PG-14 and SORs to the same level than WT cells (Table 4). The fatty acid content and composition of oil fraction were also determined: dry biomass from $P G-14$ and SOR mutants were enriched in fatty acids than the WT as follows: PG-14>SOR5/6>B1; ELgrown WT strain showed high relative amounts of C16:0 fatty acids ( $\sim 18 \%$ of total acyl chains) and high proportions of mono-unsaturated C18:1 ( 28\%) and di-unsaturated C16:2 and C18:2 fatty acids ( 44\%), which overall accounts for more than $90 \%$ of total acyl chains in C. vulgaris. Comparison of the fatty acid profiles of the mutant strains revealed that the C16:2 content was reduced in all mutants $(-15 /-35 \%$ vs. WT); while the C16:0 content was essentially unaffected. PG-14 and SOR mutants underwent changes in the $\mathrm{C} 18$ composition, with a significant increase of C18:1 in PG-14 and SOR mutants vs. WT and a corresponding decrease of C18:2 acyl chain (Additional file 1: Table S1).

\section{Discussion}

\section{Reduction of antenna size improves light-use efficiency}

Limiting factors for large-scale algal biomass production include the inefficient use of photons under mass culture conditions, due to high optical density of the cell suspension and the generation of steep light gradients. Biomass productivity can be improved by engineering optical properties of strains. Previous work targeted genes, such as TLA1 [31,32], which control antenna size in the model species $C$. reinhardtii, yielding enhanced productivity. A forward-genetic approach was adopted in species with a high market interest, such as $C$. sorokiniana and $N$. gaditana, involving random mutagenesis and screening for desired traits. Truncated antenna mutants were selected for both species, and exhibited increased photon use efficiency and biomass yield in dense cell suspensions, which are typical of industrial PBRs [22,33]. In this work, we used a similar approach with Chlorella vulgaris, a robust, interesting species for industrial applications. In 

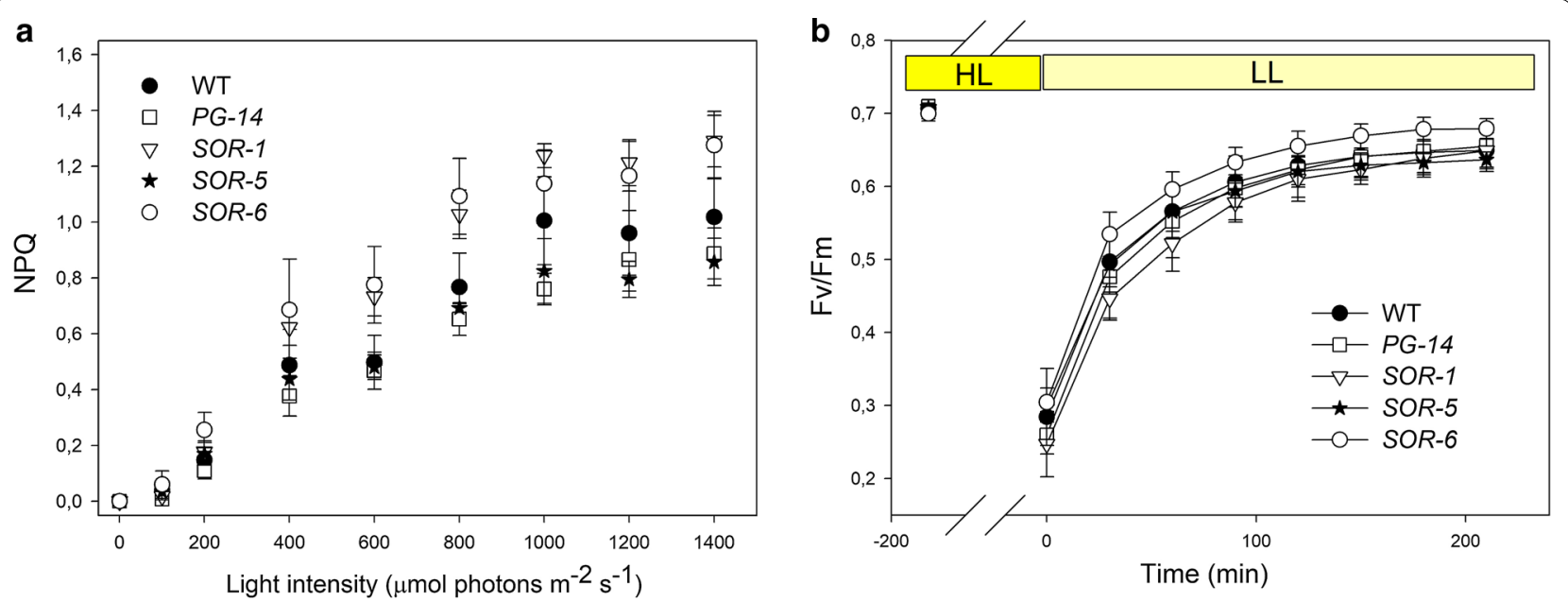

Fig. 7 Analysis of room temperature chlorophyll fluorescence during photosynthesis under EL. a Chlorophyll fluorescence was monitored at $24^{\circ} \mathrm{C}$ in dark-adapted cultures. Cell suspensions were illuminated for 20 min and the thermal energy dissipation (NPQ) was determined during steady-state photosynthesis. Symbols and error bars show mean \pm SD $(n=4)$. b PSII repair efficiency was quantified on WT, PG-14 and SOR strains plants by measuring $F_{v} / F_{m}$ (PSII photoinhibition) recovery in low light ( $L L-20 \mu \mathrm{mol}$ photons $\mathrm{m}^{-2} \mathrm{~s}^{-1}, 24^{\circ} \mathrm{C}$ ) after photoinhibitory treatment $\left(\mathrm{HL}-1800 \mu \mathrm{mol}\right.$ photons $\left.\mathrm{m}^{-2} \mathrm{~s}^{-1}, 24^{\circ} \mathrm{C}, 3 \mathrm{~h}\right)$ that reduce the $F_{\mathrm{v}} / F_{\mathrm{m}}$ value to $\sim 0,3$ in all genotypes. Data are expressed as mean $\pm \mathrm{SD}(n=4)$

Table 4 Lipid content of algal biomass

\begin{tabular}{ll}
\hline Genotype & $\begin{array}{l}\text { Total oil } \\
\text { content (\% } \\
\text { DW) }\end{array}$ \\
\hline WT & $25.1 \pm 2.7^{\mathrm{a}}$ \\
PG-14 & $23.2 \pm 0.8^{\mathrm{a}}$ \\
SOR-1 & $22.2 \pm 2.3^{\mathrm{a}}$ \\
SOR-5 & $21.9 \pm 2.2^{\mathrm{a}}$ \\
SOR-6 & $27.5 \pm 2.6^{\mathrm{a}}$ \\
\hline
\end{tabular}

Total lipid content was determined gravimetrically on the dry biomass, from WT and mutant cultures grown for 7 days in standard, nutrient-rich BG-11 medium at $1400 \mu \mathrm{mol}$ photons $\mathrm{m}^{-2} \mathrm{~s}^{-1} 25^{\circ} \mathrm{C}$, and then moved for further 4 days of growth in modified BG-11 medium with limiting N source. Data are expressed as mean $\pm S D, n=4$. Significant different values in oil content among genotypes (ANOVA test, $p<0.05$ ) are marked with different letters

a first screen, we searched for pale-green phenotype to establish a background strain for further domestication by incorporating the low optical density trait [21, 22, 32], thus increasing light penetration and light-to-biomass yield.

Among seven pale-green mutants recovered from screening 25,000 colonies, a range of reduction in Chl content between 25 and $60 \%$ with respect to WT strain was obtained (Additional file 1: Figure S1C). Clearly, reduction of Chl content per se was not sufficient for improving light-use efficiency in all strains (Additional file 1: Figure S2). In fact, four mutants ( $p 1-14, p 1-43$, $p 1-47$ and $p 2-77)$ showed a productivity higher than WT, while the others performed similar to the control genotype despite their $p g$ phenotype. Strains $p 2-25$ and p2-36 had a similar Chl content per cell as PG-14 and yet performed differently. This is consistent with the previous reports with two low $\mathrm{Chl} /$ cell mutants in Cyclotella sp. [34] whose productivity respect to WT was not improved in PBRs. Indeed, random mutagenesis may well affect multiple genes, thus influencing cell metabolism and impairing growth. Therefore, a full photosynthetic characterization of mutants obtained by chemical/UV mutagenesis is needed to ensure that pale-green mutants are not affected in their photosynthetic performance other than by reducing their LHCII content $[22,35]$. We chose PG-14 based on its defect in PSII antenna size, consisting in a LHCII content of $61 \%$ with respect to WT (Fig. 1b). Fluorescence induction in cells infiltrated with DCMU confirmed that $P G-14$ had a marked reduction of the PSII functional antenna size as compared to WT (Fig. 1a). In contrast, the PSII: PSI ratio was unaffected with respect to WT level (Fig. 1b).

Photosynthetic yield was significantly enhanced in PG14 vs. WT. Indeed, the $P_{\max }$ of $P G-14$ was $60 \%$ larger than in WT at saturating irradiances (Table 2), implying that the undercut in antenna size did not negatively impact on photosynthesis. These results are consistent with those reported for C. reinhardtii mutants tla1 [35] and tla3 [21].

Owing to the double light-harvesting and photoprotective function of LHC proteins, it is relevant to consider whether mutations increase susceptibility to photoinhibition [19] as observed in the ch1 mutation [36], by preventing LHC assembly, which leads to overproduction of ${ }^{1} \mathrm{O}_{2}$ and enhanced photooxidation [37]. 
The light-saturation curve of photosynthesis showed no decline of $\mathrm{O}_{2}$ evolution even at very high light intensity (6000 $\mu \mathrm{mol}$ photons $\mathrm{m}^{-2} \mathrm{~s}^{-1}$, Fig. 1c), whereas the lipid peroxidation and rate of $\mathrm{Chl}$ photobleaching were the same in PG-14 and WT cultures exposed to high light (Fig. 4). We conclude that $50 \%$ loss of LHC per PSII does not significantly affect photo-tolerance of $C$. vulgaris cells under the tested growth conditions. Finally, cell growth rates and biomass yield were measured in the long-term cultivation of dense algal suspensions under very high irradiance $\left(1400 \mu \mathrm{mol}\right.$ photons $\left.\mathrm{m}^{-2} \mathrm{~s}^{-1}\right)$. During 8 days of growth, PG-14 showed a significant increase of productivity with respect to WT, both as biomass increment per day and maximal level of biomass reached at the end of the growth period (Fig. 1d, Table 3). In conclusion, characterization of C. vulgaris PG-14 strain confirmed that selection for reduced optical cell density is a viable strategy to obtain higher productivity.

\section{Enhanced resistance to oxidative stress differently affects the growth rate}

How do the SOR mutations contribute to the increased growth rate relative to $P G-14$ ? Photosynthetic organisms have evolved a number of photoprotective mechanisms to limit photooxidative damage [15], the latter being an unavoidable consequence of the presence of highly reactive intermediates during oxygenic photosynthesis. These mechanisms are active in (i) preventing over-excitation of reaction centers by quenching either ${ }^{1} \mathrm{Chl}^{*}[16]$ or ${ }^{3} \mathrm{Chl}{ }^{*}$ states [37], thus avoiding ROS formation, or (ii) detoxifying ROS [38]. The first class includes the activation of energy dissipation into heat thus relieving the excitation pressure on PSII [16], and long-term physiological acclimation processes, some of which induce the re-organization of the photosynthetic apparatus [15] upon triggering by signal pathways activated by oxidative products [39]. The antioxidant defence mechanisms include enzymatic(APX, SOD, CAT, etc.) and non-enzymatic antioxidants (carotenoids, tocopherols, ascorbate, glutathione) [40]; in particular, the thylakoid-bound antioxidants carotenes and xanthophylls play an irreplaceable role as structural components of the photosynthetic apparatus and photoprotective molecules, crucial in both quenching ${ }^{1} \mathrm{O}_{2}$ and inhibiting lipid peroxidation [41].

Among the first class of mechanisms, possibly underlying the higher biomass yield of SORs, NPQ is the most relevant. NPQ catalyzes dissipation, in form of heat, of the light energy absorbed in excess. In microalgae, the mechanism is activate by LhcSR (light-harvesting complex stress-related) protein [42]. In WT, PG-14 and SOR genotypes, NPQ amplitude was measured at steady-state photosynthesis over a range of irradiances, showing differences mostly negligible (Fig. 7a), consistent with the similar LhcSR content in all the strains (Additional file 1: Figure S3). Thus, we conclude that the differences in growth of $S O R$ lines were not due to enhanced NPQ.

The antioxidant activity of PG-14 and SOR mutants was in general higher than the WT, irrespective of the antioxidant assay used. SOR-1 showed the highest antioxidant power when tested with FRAP, a reagent that evaluates the antioxidant activity by reducing a metallic ion (Fig. 5a). This assay has been used to evaluate both lipophilic substances such as tocopherol as well as more polar antioxidants as ascorbic acid [43]. On the other hand, PG-14 showed the highest antioxidant activity with the ABTS assay (Fig. 5b). The latter assay reacts with both phenolic compounds and carotenoids [44] and correlates with the higher content of carotenoids of this mutant with respect to WT (Table 1). However, since the carotenoid level of all mutants is not significantly different (Table 1), other compounds (e.g., phenolics or other natural antioxidants) might be more abundant in PG-14 cells than SOR mutants. Lower MDA accumulation and higher resistance to photobleaching in EL (Fig. 5) suggest either a reduced ${ }^{1} \mathrm{O}_{2}$ release of $S O R$ vs. PG-14 and WT, or a more effective scavenging activity of ${ }^{1} \mathrm{O}_{2}$ in the chloroplasts, being this ROS unstable and suggested as unable to leave the plastid compartment [45]. Reduced ${ }^{1} \mathrm{O}_{2}$ release within the chloroplasts appears unlikely, being content of the major photosynthetic components identical in PG-14 and SOR strains (Additional file 1: Figure S3). Regarding the antioxidant capacity, it is worth noting that SOR-6 cells, namely the fastest-growing strain, did not show higher antioxidant ability than the control genotype PG-14, with both methods used; the other two SOR strains showed a slightly higher antioxidant capacity when probed by FRAP methods, while lower capacity than PG-14 when probed by ABTS. Similar results were obtained with other two antioxidant assays, namely DPPH and Folin-Ciocalteau (data not shown). In an attempt to reconcile such contrasting results, it can be hypothesized the antioxidant assays here chosen is more sensitive to specific ROS, thus might have underestimated the contribution of ${ }^{1} \mathrm{O}_{2}$-specific detoxification mechanisms, although more active in SOR mutants. Alternatively, the scavenging potential of SOR cells might not be the main factor improving photosynthetic performance in EL.

The higher resistance of SOR strains to photooxidative stress was not due to enhanced capacity for PSII repair process: indeed, the recovery of $F_{\mathrm{v}} / F_{\mathrm{m}}$ (quantum yield of PSII) upon photoinhibitory treatment showed that all genotypes showed a similar behavior (Fig. 7b).

Interestingly, these mutants showed a biomass productivity significantly higher with respect to the corresponding value for the $P G-14$ even when grown in 
limiting-light conditions $\left(50 \mu \mathrm{mol}\right.$ photons $\left.\mathrm{m}^{-2} \mathrm{~s}^{-1}\right)$, showing biomass productivities similar to WT culture (Fig. 6b, Table 3). Similar results were obtained in growth assay carried out at lower irradiance $(20 \mu \mathrm{mol}$ photons $\mathrm{m}^{-2} \mathrm{~s}^{-1}$, data not shown). These results are unexpected in mutants with truncated light-harvesting antenna size, in which photosynthetic efficiency decreases at sub-saturating irradiances due to limitation in PSII cross section.

Indeed, enhanced growth in low light despite truncation in antenna size suggests that the enhanced light-use efficiency is obtained in SOR genotypes, and contributes to the enhanced biomass production. Clearly, this is not due to enhanced PSII repair not to decreased NPQ with respect to WT and PG-14, and its nature is unclear based on present results. Hypothesis includes altered thylakoid architecture, change in composition or relative abundance of LHC proteins, altered kinetic in the remodeling of photosynthetic membranes in response to illumination [46] or up-regulation of plastidial regulatory elements $[47,48]$. The elucidation of this mechanism will be the object of further analysis including identification of mutations and physiological analysis of these genes, to identify genetic elements potentially useful for enhancing primary productivity.

Alternatively, higher biomass yield in EL might not be exclusively due to either improved antioxidant networks or enhanced light-use efficiency in SOR strains. Pal et al. [49] showed that activation of stress response upon ${ }^{1} \mathrm{O}_{2}$ induction was effective in increasing resistance to oxidative stress in $C$. reinhardtii without altering antioxidant levels. Indeed, depending on its concentration, ${ }^{1} \mathrm{O}_{2}$ may either cause oxidative damage or act as "second messenger" in cell signal transduction. In algae, similar to reports on plants [50], PSII is the cellular major source of ${ }^{1} \mathrm{O}_{2}$. However, due to its high reactivity and short lifetime, ${ }^{1} \mathrm{O}_{2}$ is not considered as directly involved in chloroplast-to-nucleus signaling; rather, plant cells perceive ${ }^{1} \mathrm{O}_{2}$ as signal which controls a number of stress-response mechanisms [51]: in Arabidopsis, EXECUTER proteins (EX1 and EX2) are involved in the regulation of the ${ }^{1} \mathrm{O}_{2}$-mediated genetic response [52, 53]; in Chlamydomonas, specific responses to ${ }^{1} \mathrm{O}_{2}$ vs. other ROS was attributed to specific promoter regions [54, 55]. Moreover, a moderated ${ }^{1} \mathrm{O}_{2}$ release under EL stress affects susceptibility of $C$. reinhardtii cells to subsequent, more severe stresses [49]. In plants, induction of stress acclimation allowed higher protection against PSII photoinhibition upon harsher conditions: acclimation activates a subset of ${ }^{1} \mathrm{O}_{2}$-responsive genes in WT plants, while represses them in ex1/ex2 plants. However, the extent of photosensitivity in WT and ex1/ex2 plants was the same upon acclimation [53], thus suggesting that it relies on extensive cross-talk with different stress-related signaling pathways.

A set of plastid-derived signals were found to be involved in the adaptation of cell physiology to the changing environmental conditions: these include tetrapyrroles, metabolites such as 3-phosphoadenosine5-P (PAP) and methylerythritol cyclo-PP, ROS and cleavage products of carotenes and/or phytofluene, as well the redox state of stroma and the organellar gene expression (reviewed in $[56,57]$. Under photooxidative stress, oxidized derivatives of $\beta$-carotene such as $\beta$-cyclocitral $(\beta-\mathrm{CC}), \beta$-ionone and dihydroactinidiolide (dhA) act as signaling molecules, inducing transcriptomic responses associated with enhanced resistance to photoxidative stress [39, 58, 59]. Release of carotenoid oxidation products was reported not only in plants but also in cyanobacteria [60], while the small zinc finger proteins MBS were shown to mediate the ${ }^{1} \mathrm{O}_{2}$-dependent transcriptomic response in both Chlamydomonas and plants, thus suggesting these sensing mechanisms are ubiquitous in the green lineage.

The task of identifying the signaling pathway affected in SOR mutants is complex due to integration of multiple signaling cascades whose components are still poorly understood and involving considerable cross-talk aimed at sustaining cell homeostasis during stress responses as shown by interaction between elements of PAP and $\beta-C C$ retrograde signaling. Such interactions promote gene reprogramming and enhance tolerance to photoinhibition as shown by the positive effect of pre-treatment with either PAP or $\beta$-CC before stress treatment $[58,61]$.

We speculate that higher phototolerance in SOR mutants might be related to a constitutive activation of one or more of the above-mentioned signal transduction pathways. High-productivity phenotype of SORs suggests that multiple defense processes might be affected, possibly due to mutations in global regulators of photoprotection response in algal cell. Future identification of these mutations will possibly allow pinpointing new components of ${ }^{1} \mathrm{O}_{2}$-mediated signaling control and their role in different cellular protection mechanisms.

\section{Influence of ROS-resistance traits on stress-induced lipid production}

While excessive ROS release causes irreversible damage to cellular structures, ROS formed under mild photooxidative stress conditions promote lipid accumulation in oleaginous microorganisms [62], possibly by a complex signaling pathway that triggers up-regulation of the enzyme ACCase and increases $C$ flux into the pathway of fatty acid biosynthesis [63]. Indeed, [30] found that intracellular lipid content in C. vulgaris is correlated with hydroxyl radical levels. Moreover, oxidative stress 
perception by the endoplasmic reticulum promotes lipid droplets formation [64]. Overall, direct experimental evidences of an association between ROS and intracellular lipids are still scarce, and details on the molecular mechanisms of ROS-mediated lipid accumulation are missing. However, if ROS are obligate mediators of lipid accumulation by complex signaling pathways, then we might expect an altered lipid yield in an individual mutant possibly affected in such stress-response pathways. Quantification of oil content, upon short-term nitrogen-starvation treatment of cultures, ruled out the hypothesis: indeed, oil content was essentially the same in all strains analyzed, while fatty acid content of dry biomass was significantly higher in all mutants than WT. We only measured a decrease of C16:2 acyl chain fraction in mutant strains vs. WT; a significant increase of C18:1 acyl chain in mutants vs. WT and a corresponding decrease of C18:2 acyl chain, the most abundant PUFA of C. vulgaris, was also shown. These results contrast with former evidence that higher ROS release obstructs PUFA biosynthesis [65]: indeed, kinetic of MDA formation in EL suggests PUFA peroxidation is lower in $S O R$ vs. WT and $P G-14$ strains. Rather, such a change in lipid composition points again to an altered signaling cues in SORs with respect to control genotypes.

\section{Conclusions}

Our results show that domestication of WT strains, by both modulating antenna size to improve light penetration and enhancing resistance to excess light, is an effective strategy in the development of microalgal strains optimized for mass culture and these effects are additive towards a higher biomass productivity and stress resistance. Further work will be undertaken for the identification of genes affected in the SOR mutants by DNA and RNA sequencing. Owing to the impossibility of carrying on genetic crossing in Chlorella, pyramiding positive traits will need reliable transformation and gene editing procedures that are still to be implemented in this genus. Moreover, we have shown a specific effect for SOR mutations in improving light-use efficiency. Indeed, besides the enhanced ${ }^{1} \mathrm{O}_{2}$ scavenging effect of SOR genotypes, an additional, still unknown, mechanism is needed to explain their higher growth rates in limiting-light conditions. Identification of this mechanism will be the subject of future research.

\section{Materials and methods}

\section{Strains and culture conditions}

Chlorella vulgaris WT strain was obtained from the SAG Culture Collection of Algae (Goettingen University, Germany, http://www.uni-goettingen.de/en/catal ogue-of-strains/185049.html) as SAG strain number 211-11p. Cells were maintained on TAP-agar plates [66] and grown in either minimal (BG-11) [67] or rich (TAP) media. Shaken flasks $(120 \mathrm{rpm})$ were illuminated from the top with $100 \mu \mathrm{mol}$ photons $\mathrm{m}^{-2} \mathrm{~s}^{-1}$, photoperiod of $16 / 8 \mathrm{~h}$ light/dark, $25{ }^{\circ} \mathrm{C}$; irradiance was provided by warm-white LEDs (Epistar 35mil Chip High Power LED, warm white LEDE-P20B-DW, Wayjun Tech., Shenzhen, China). For all physiological and biochemical measurements, cultures were harvested during the logarithmic growth phase $\left(\sim 1 \cdot 10^{8}\right.$ cells $\left.\mathrm{mL}^{-1}\right)$. For short-term nitrogen-starvation experiments, cells were grown for 4 days in standard BG-11 medium containing excess nitrogen source $\left(\mathrm{NaNO}_{3} 1.5 \mathrm{~g} \mathrm{~L}^{-1}\right)$ at an irradiance of $1400 \mu \mathrm{mol}$ photons $\mathrm{m}^{-2} \mathrm{~s}^{-1}, 25{ }^{\circ} \mathrm{C}$, with a photoperiod of $16 / 8 \mathrm{~h}$ light/dark; cells were then collected by centrifugation, washed twice with sterile water, and re-suspended at $1 \cdot 10^{8}$ cells $\mathrm{mL}^{-1}$ in a modified BG-11 medium with limiting $\mathrm{N}$ source $\left(\mathrm{NaNO}_{3} 0.07 \mathrm{~g} \mathrm{~L}^{-1}\right)$ and further grown for 3 days.

\section{Mutagenesis and screening protocols}

C. vulgaris WT cells in liquid cultures were harvested by centrifugation at the exponential phase of growth $\left(\sim 1.10^{8}\right.$ cells $\left.\mathrm{mL}^{-1}\right)$, re-suspended in fresh TAP medium to $5 \cdot 10^{7}$ cells $\mathrm{mL}^{-1}$, and treated with ethyl methanesulfonate (EMS). The survival curve for mutagenesis with EMS was carried out to determine the mutagen concentration which resulted in around $5 \%$ of cells viability. Upon 2-h maintenance in the dark, to prevent light-activated DNA repair, cells were plated at 100 -fold dilution on TAP-agar medium and exposed to $100 \mu \mathrm{mol}$ photons $\mathrm{m}^{-2} \mathrm{~s}^{-1}$. Single colonies appeared after 14 days. The ones showing a pale-green phenotype were identified by direct sight inspection, inoculated onto fresh minimal medium, grown in the light for seven days, and the Chl content per cell was determined. This procedure allowed to isolate the pale-green mutant strain PG-14. Chemical mutagenesis was repeated on the strain $P G-14$ to isolate singlet oxygen-resistant mutant strains. The photosensitizer Red Bengal (RB) was used as selection method: RB is a chemical producing ${ }^{1} \mathrm{O}_{2}$ when exposed to white light [68]; thus, the screening of the mutants was performed by their resistance to the exogenous ${ }^{1} \mathrm{O}_{2}$. A wide range of concentrations of chemical were tested to find out the minimal concentration which inhibited grown of the PG-14 strain. SOR (singlet oxygen resistant) mutants were selected by plating mutagenized PG-14 cells on TAP-agar plates containing $12 \mu \mathrm{M} \mathrm{RB}$, which were then exposed to $100 \mu \mathrm{mol}$ photons $\mathrm{m}^{-2} \mathrm{~s}^{-1}$ to initiate the selection for resistant clones. ${ }^{1} \mathrm{O}_{2}$-resistance of selected mutants was tested by serial dilution of a concentrated culture $\left(\sim 5 \cdot 10^{7}\right.$ cells $\mathrm{mL}^{-1}$ ), spotted onto plates containing $12 \mu \mathrm{M} R B$ and maintained in the light for several days. Estimation 
of resistance to exogenously generated ${ }^{1} \mathrm{O}_{2}$ was done by transferring aliquots of culture $\left(5 \cdot 10^{7}\right.$ cells $\left.\mathrm{mL}^{-1}\right)$ into a multi-well plate and adding RB $(0-50 \mu \mathrm{M})$. Cells were grown for $24 \mathrm{~h}$ at $100 \mu \mathrm{mol}$ photons $\mathrm{m}^{-2} \mathrm{~s}^{-1}$, then $10 \mu \mathrm{L}$ from each well were spotted on TAP-agar plates.

\section{Cell count and pigment analysis}

Cell density was measured using an improved Neubauer hemocytometer. Pigments were extracted from intact cells with $100 \%$ dimethyl-formamide. The supernatant of each sample was recovered after centrifugation (10 $\mathrm{min}$ at $15,000 \mathrm{~g}, 4{ }^{\circ} \mathrm{C}$ ), diluted in acetone and pigments were separated and quantified by HPLC [69].

\section{Gel Electrophoresis and Immunoblotting}

For SDS-PAGE and immunotitration analysis, cells were resuspended in Loading Buffer (5\% glycerol, 1\% SDS, 2.5\% 2-mercaptoethanol, 0.1 M Tris, 0.1 M Tricine $\mathrm{pH}$ 8.45 ) and grinded in a tissue homogenizer (Precellys, Bertin, France) by adding a ceramic lysing matrix. The supernatant of each sample was recovered after centrifugation $\left(10 \mathrm{~min}\right.$ at $15,000 \mathrm{~g}, 4^{\circ} \mathrm{C}$ ) and $\mathrm{Chl}$ content of extracts was determined. SDS-PAGE analysis was performed with the Tris-Tricine buffer system [70]. For immunotitration [71], a range of total protein extract corresponding to 0.1-2.0 $\mu \mathrm{g}$ of Chl were loaded for each sample and electroblotted on nitrocellulose membranes. Proteins were detected with primary antibodies (home-made: $\alpha$-CP43, $\alpha$-Rubisco, $\alpha$-LhcSR; from Agrisera: $\alpha$-PsaA AS06-172$100, \alpha$-Cyt $f$ AS06-119, $\alpha$-ATPase $\beta$ subunit AS05-085) and an alkaline phosphatase-conjugated secondary antibody (Sigma-Aldrich A3687). Signal amplitude was quantified using the GelPro 3.2 software (Bio-Rad).

\section{Measurements of photosynthetic activity}

The oxygen evolution activity of the cultures was measured at $25^{\circ} \mathrm{C}$ with a Clark-type $\mathrm{O}_{2}$ electrode (Hansatech, UK) upon illumination with white light provided by a halogen lamp (Schott, Germany). Samples of $2 \mathrm{~mL}$ cell suspension $\left(\sim 5 \cdot 10^{7}\right.$ cell $\left.\mathrm{mL}^{-1}\right)$ were loaded into the oxygen electrode chamber; $3 \mathrm{mM} \mathrm{NaHCO}_{3}$ was added to the cell suspension prior to the $\mathrm{O}_{2}$ evolution measurements to ensure electron transport was not limited by the carbon supply.

\section{In vivo chlorophyll fluorescence analysis}

Fluorescence induction kinetics was recorded with a home-built apparatus as previously described [72]. Variable fluorescence was induced with a green light of $7 \mu \mathrm{mol}$ photons $\mathrm{m}^{-2} \mathrm{~s}^{-1}$ at RT, on cells suspensions $\left(\sim 5 \cdot 10^{7}\right.$ cells $\mathrm{mL}^{-1}$ ) in BG-11 medium containing $100 \mu \mathrm{M}$ DCMU. The reciprocal of time corresponding to two-thirds of the fluorescence rise $\left(T_{2 / 3}\right)$ was taken as a measure of the PSII functional antenna size [25]. Quantum efficiency of PSII $\left(F_{\mathrm{v}} / F_{\mathrm{m}}\right)$ was measured on cell suspension, darkadapted for 20 min, with a PAM 101 fluorimeter (HeinzWalz, Germany). The light dependence of NPQ during photosynthesis was measured through Chl fluorescence on dark-adapted cell suspension at RT with a FluorCam 700MF (Photon Systems Instruments, Brno, Czech Republic); NPQ was calculated according to [73] at steady-state photosynthesis (upon 20 min illumination).

\section{Determination of the sensitivity to photooxidative stress}

The extent of lipid peroxidation in cells was estimated by measuring malondialdehyde (MDA) formation, as an indirect quantification of lipid peroxides [74]. Quantitative evaluation was done by transferring $2 \mathrm{~mL}$ aliquots of WT and mutant cell suspensions $\left(\sim 5 \cdot 10^{7}\right.$ cell $\mathrm{mL}^{-1}$, in BG-11) into a 24-well culture plate, kept on a rotary shaker and illuminated for 2 days with high light $\left(1400 \mu \mathrm{mol}\right.$ photons $\left.\mathrm{m}^{-2} \mathrm{~s}^{-1}, 25{ }^{\circ} \mathrm{C}\right)$. Samples $\left(2 \cdot 10^{5}\right.$ cells) were taken for analysis during a period of $48 \mathrm{~h}$, and frozen in liquid nitrogen. MDA content of aliquots was quantified as previously described [75].

The photobleaching kinetics of $\mathrm{Chl}$ cell content were measured on cell suspensions $\left(\sim 5 \cdot 10^{7}\right.$ cell $\mathrm{mL}^{-1}$, in BG- $11+0.03 \% \mathrm{w} / \mathrm{v}$ agarose) using actinic light intensities of $14,000 \mu \mathrm{mol}$ of photons $\mathrm{m}^{-2} \mathrm{~s}^{-1}$ for $2 \mathrm{~h}$; temperature of samples was maintained at $25{ }^{\circ} \mathrm{C}$. During the illumination, the absorbance area between 600 and 750 was recorded; the initial and maximal absorbance were set, so the same absorbance area was used in the wavelength range $600 \mathrm{~nm}<\lambda<750 \mathrm{~nm}$ for all the samples.

\section{Growth analysis}

Growth experiments were performed at $25^{\circ} \mathrm{C}$ in a homebuilt photobioreactors, composed of glass cylinders with a maximum light path of $8 \mathrm{~cm}$ and a working volume of 1 liter each [22]. Cultures were continuously mixed with a flux of air and $\mathrm{CO}_{2}$. The ratio of compressed air and $\mathrm{CO}_{2}$ was automatically adjusted to keep the $\mathrm{pH}$ of the medium within the range 6.8-7.2. Each autotrophic batch cultivation was carried out in duplicate. Illumination was provided by a panel of warm-white LEDs (Epistar 35mil Chip High Power LED, warm white LEDE-P20B-DW), microalgae were exposed to an irradiance of $1400 \mu \mathrm{mol}$ photons $\mathrm{m}^{-2} \mathrm{~s}^{-1}$, with a photoperiod of $16 / 8 \mathrm{~h}$ light/ dark. The parameters determined to monitor cell growth were cell number and dry biomass weight, for which the washed cell pellets were dried overnight in a lyophilizer. The inoculum size was $1 \cdot 10^{6}$ cell $\mathrm{mL}^{-1}$. 
Determination of total lipid content and lipid composition Total lipids were extracted from $100 \mathrm{mg}$ lyophilized biomass from 3 days nitrogen-starved cultures, homogenized by 4 cycles of $30 \mathrm{~s}$ at $8000 \mathrm{rpm}$, with a Precellys homogenizer (Bertin, France) using the extraction protocol by [76], with a total of $3 \mathrm{~mL}$ methanol, $6 \mathrm{~mL}$ chloroform and a subsequent washing step with $4 \mathrm{~mL}$ water. Net total lipid amount was determined gravimetrically.

To determine lipid composition, lyophilized biomass was extracted with a Soxhlet apparatus using $\mathrm{CHCl}_{3}$-hexane $(2: 1 \mathrm{v} / \mathrm{v})$. The extract was evaporated under $\mathrm{N}_{2}$ and weighted and resuspended in hexane. Fatty acid methyl esters (FAME) were obtained, after addition of an aliquot of the internal standard heptadecanoate, by treatment with $\mathrm{MeOH}-\mathrm{BF}_{3}$ according to the method described by [77]. The quantitative determination of FAME was obtained by gas chromatography using a flame ionization detector (FID-GC). A ZB5-MS 30-m column was used with the following temperature program: $60{ }^{\circ} \mathrm{C}$ for $1 \mathrm{~min}$, then an increasing rate of $10{ }^{\circ} \mathrm{C}$ $\mathrm{min}^{-1}$ up to $180{ }^{\circ} \mathrm{C}$, a second increase of $1{ }^{\circ} \mathrm{C} \min ^{-1}$ up to $230{ }^{\circ} \mathrm{C}$, then $15{ }^{\circ} \mathrm{C} \mathrm{min}{ }^{-1}$ to reach $290{ }^{\circ} \mathrm{C}$. The injector temperature was $280{ }^{\circ} \mathrm{C}$, the detector temperature was $280^{\circ} \mathrm{C}$; the carrier gas was He with a flow rate of $1 \mathrm{~mL} \mathrm{m^{-1 }}{ }^{-1}$; splitless injection mode. Based on internal standard area, FAME from FFA, MAG, DAG and TAG were quantitatively estimated on an algae dry weight basis. Compounds were identified by both retention times, comparison of pure standards and gas chromatography coupled to mass spectrometry (GC-MS). Carrier gas was He with a constant flow of $1 \mathrm{~mL} \mathrm{~min}{ }^{-1}$, transfer line temperature to MSD was $280{ }^{\circ} \mathrm{C}$, ionization energy $70 \mathrm{eV}$, and full scan range $50-500 \mathrm{~m} / \mathrm{z}$.

\section{Determination of antioxidant activity}

Free radical scavenging activities of lyophilized algae, grown at an irradiance of $1400 \mu \mathrm{mol}$ photons $\mathrm{m}^{-2} \mathrm{~s}^{-1}$, were determined using the radical species 2,2'-azinobis(3-ethylbenzothiazoline-6-sulfonic acid) $\left(\mathrm{ABTS}^{\cdot+}\right.$ ) assay as described by [44]. The reducing activity of ethanolic extracts was assessed using FRAP method [43]. FRAP was freshly prepared by mixing (8:1:1, v/v) $0.3 \mathrm{M}$ acetate buffer ( $\mathrm{pH} 3.6), 10 \mathrm{mM}$ 2,4,6-tripyridyl-s-triazine (TPTZ) and $20 \mathrm{mM} \mathrm{FeCl}_{3}$. All data are expressed as $\mu$ mol Trolox Equivalents (TE) per g of WT alga. All measurements were repeated three times.

\section{Statistics}

Significance analysis was performed using either Student's $t$ test or ANOVA test in GraphPad Prism software. Error bars represent the standard deviation.

\section{Supplementary information}

Supplementary information accompanies this paper at https://doi. org/10.1186/s13068-019-1566-9.

Additional file 1: Figure S1. Screening strategy used to isolate palegreen mutant of $C$. vulgaris. Figure S2. Growth curves of WT and palegreen mutants of $\mathrm{C}$. vulgaris, under autotrophic conditions. Figure S3. Immunotitration of major photosynthetic subunits. Table S1. Acyl chain composition of lipid fraction from WT and mutants PG-14 and SOR.

\section{Abbreviations}

$\beta$-CC: $\beta$-cyclocitral; Car: carotenoids; Chl: chlorophylls; DCMU:

3-(3,4-dichlorophenyl)-1,1-dimethylurea; dhA: dihydroactinidiolide; DW: dry weight; EL: excess light; EMS: ethyl metanesulfonate; $F_{\mathrm{v}} / F_{\mathrm{m}}$ : maximal quantum yield of PSII; LHCI/I: light-harvesting complex of PSI/I; MDA: malondialdehyde; NPQ: non-photochemical quenching; $P_{\max }$ : maximal photosynthetic rate; PAP: 3-phosphoadenosine-5-P; PAR: photosynthetic active radiation; PBR: photobioreactor; PG: pale green; PSI/II: photosystem I/II; RB: Red Bengal; ROS: reactive oxygen species; SOR: singlet oxygen resistant; WT: wild-type; ${ }^{1} \mathrm{Ch}{ }^{*}$ : singlet excited state of $\mathrm{Chl}^{3}{ }^{3} \mathrm{Chl}{ }^{*}$ : triplet excited state of $\mathrm{Chl}^{1}{ }^{1} \mathrm{O}_{2}$ : singlet oxygen.

\section{Acknowledgements}

Not applicable.

\section{Authors' contributions}

$L D, S C$ and ZG performed identification and isolation of all the genotypes used; MB, SB and SC carried out the biochemical and photosynthetic characterization of strains and drafted the manuscript; GM and MEM carried out antioxidant assays and lipidomic analysis; LD and RB conceived the study, participated in its design and coordination and edited the manuscript. All authors read and approved the final manuscript.

\section{Funding}

Financial support for this work was provided by the Marie Curie Actions Initial Training Networks SE2B (H2020-MSCA-ITN-2015-GA N. 675006), the University of Verona (Fondo Ricerca di Base HuntingLight) and "Programma Operativo Regionale FSE 2014-2020" (Grant No. 1695-16-2216-2016) from Regione del veneto.

\section{Availability of data and materials}

The datasets analyzed during the current study available from the corresponding author on reasonable request.

Ethics approval and consent to partecipate

Not applicable.

\section{Consent for publication}

Not applicable.

\section{Competing interests}

The authors declare that they have no competing interests.

\section{Author details}

${ }_{1}^{1}$ Dipartimento di Biotecnologie, Università di Verona, Strada Le Grazie 15, 37134 Verona, Italy. ${ }^{2}$ Dipartimento di Scienze della Vita e Biologia dei Sistemi, Unità di Fisiologia Vegetale, Università di Torino, Via Quarello 15/a, 10135 Turin, Italy.

Received: 22 May 2019 Accepted: 7 September 2019

Published online: 16 September 2019

\section{References}

1. Sivakumar G, Xu JF, Thompson RW, Yang Y, Randol-Smith P, Weathers PJ. Integrated green algal technology for bioremediation and biofuel. Biores Technol. 2012;107:1-9. 
2. Hambourger M, Moore GF, Kramer DM, Gust D, Moore AL, Moore TA. Biology and technology for photochemical fuel production. Chem Soc Rev. 2009;38(1):25-35.

3. Chisti Y. Biodiesel from microalgae beats bioethanol. Trends Biotechnol. 2008;26(3):126-31.

4. Jones CS, Mayfield SP. Algae biofuels: versatility for the future of bioenergy. Curr. Opinion Biotech. 2012;23(3):346-51.

5. Benedetti M, Vecchi V, Barera S, Dall'Osto L. Biomass from microalgae: the potential of domestication towards sustainable biofactories. Microb Cell Factor. 2018;17(1):173.

6. Nelson N, Ben SA. The complex architecture of oxygenic photosynthesis. Nature. 2004;5:1-12

7. Scott SA, Davey MP, Dennis JS, Horst I, Howe CJ, Lea-Smith DJ, Smith AG. Biodiesel from algae: challenges and prospects. Curr Opinion Biotechnol. 2010;21(3):277-86.

8. Passos F, Uggetti E, Carrere H, Ferrer I. Pretreatment of microalgae to improve biogas production: a review. Bioresour Technol. 2014;172:403-12.

9. Christenson L, Sims R. Production and harvesting of microalgae for wastewater treatment, biofuels, and bioproducts. Biotechnol Adv. 2011;29(6):686-702.

10. Pittman JK, Dean AP, Osundeko O. The potenrial of sustainable algal biofuel production using wastewater resources. Bioresour Technol. 2011:102:17-25

11. Munkel R, Schmid-Staiger U, Werner A, Hirth T. Optimization of outdoor cultivation in flat panel airlift reactors for lipid production by Chlorella vulgaris. Biotechnol Bioeng. 2013;1 10(11):2882-93.

12. Rodolfi L, Chini Zittelli G, Bassi N, Padovani G, Biondi N, Bonini G, Tredici MR. Microalgae for oil: strain selection, induction of lipid synthesis and outdoor mass cultivation in a low-cost photobioreactor. Biotechnol Bioeng. 2009:102(1):100-12.

13. Weyer KM, Bush DR, Darzins A, Willson BD. Theoretical maximum algal oil production. Bioenergy Res. 2010:3:204-13.

14. Stephenson PG, Moore CM, Terry MJ, Zubkov MV, Bibby TS. Improving photosynthesis for algal biofuels: toward a green revolution. Trends Biotechnol. 2011;29(12):615-23.

15. Li ZR, Wakao S, Fischer BB, Niyogi KK. Sensing and responding to excess Light. Ann Rev Plant Biol. 2009;60:239-60.

16. Ruban AV, Johnson MP, Duffy CD. The photoprotective molecular switch in the photosystem II antenna. Biochim Biophys Acta. 2012;1817(1):167-81.

17. Van Amerongen $\mathrm{H}$, Croce R. Light-harvesting in photosystem II. Photosynt Res. 2013;116(2-3):251-63.

18. Formighieri C, Franck F, Bassi R. Regulation of the pigment optical density of an algal cell: filling the gap between photosynthetic productivity in the laboratory and in mass culture. J Biotechnol. 2012;162(1):115-23.

19. Krieger-Liszkay A, Fufezan C, Trebst A. Singlet oxygen production in photosystem II and related protection mechanism. Photosynth Res. 2008;98(1-3):551-64

20. Aro E-M, Virgin I, and Andersson B. Photoinhibition of Photosystem II-inactivation, protein damage and turnover. Biochim.Biophys.Acta. 1993;1143:113-34

21. Kirst H, Garcia-Cerdan JG, Zurbriggen A, Ruehle T, Melis A. Truncated photosystem chlorophyll antenna size in the green microalga Chlamydomonas reinhardtii upon deletion of the TLA3-CpSRP43 gene. Plant Physiol. 2012;160(4):2251-60

22. Cazzaniga S, Dall'Osto L, Szaub J, Scibilia L, Purton S, Bassi R. Domestication of the green alga Chlorella sorokiniana: reduction of antenna size improves light-use efficiency in a photobioreactor. Biotechnol Biofuels. 2014;7:1

23. Kulheim C, Agren J, Jansson S. Rapid regulation of light harvesting and plant fitness in the field. Science. 2002:297(5578):91-3.

24. Zhu XG, Ort DR, Whitmarsh J, Long SP. The slow reversibility of photosystem II thermal energy dissipation on transfer from high to low light may cause large losses in carbon gain by crop canopies: a theoretical analysis. J Exp Bot. 2004;55(400):1167-75.

25. Malkin S, Armond PA, Mooney HA, Fork DC. Photosystem II photosynthetic unit sizes from fluorescence induction in leaves. Correlation to photosynthetic capacity. Plant Physiol. 1981;67:570-9.
26. Damiani MC, Popovich CA, Constenla D, Leonardi PI. Lipid analysis in Haematococcuspluvialis to assess its potential use as a biodiesel feedstock. Bioresour Technol. 2010;101(11):3801-7.

27. Solovchenko A, Khozin-Goldberg I, Recht L, Boussiba S. Stress-induced changes in optical properties, pigment and fatty acid content of Nannochloropsis sp: implications for non-destructive assay of total fatty acids. Marine Biotechnol. 2011;13(3):527-35.

28. Hu Q, Sommerfeld M, Jarvis E, Ghirardi M, Posewitz M, Seibert M, Darzins A. Microalgal triacylglycerols as feedstocks for biofuel production: perspectives and advances. Plant J. 2008;54(4):621-39.

29. Bona F, Capuzzo A, Franchino M, Maffei ME. Semicontinuous nitrogen limitation as convenient operation strategy to maximize fatty acid production in Neochloris oleoabundans. Algal Res. 2014;5:1-6.

30. Menon KR, Balan R, Suraishkumar GK. Stress induced lipid production in Chlorella vulgaris: relationship with specific intracellular reactive species levels. Biotechnol Bioeng. 2013;110(6):1627-36.

31. Melis A. Solar energy conversion efficiencies in photosynthesis: minimizing the chlorophyll antennae to maximize efficiency. Plant Sci. 2009;177(4):272-80.

32. Mitra M, Kirst H, Dewez D, Melis A. Modulation of the light-harvesting chlorophyll antenna size in Chlamydomonas reinhardtii by TLA1 gene over-expression and RNA interference. Phil Trans R Soc B. 2012;367(1608):3430-43.

33. Perin G, Bellan A, Segalla A, Meneghesso A, Alboresi A, Morosinotto T. Generation of random mutants to improve light-use efficiency of Nannochloropsis gaditana cultures for biofuel production. Biotechnol Biofuels. 2015:8:161.

34. Huesemann MH, Hausmann TS, Bartha R, Aksoy M, Weissman JC, Benemann JR. Biomass productivities in wild type and pigment mutant of Cyclotella sp (Diatom). Appl Biochem Biotechnol. 2009;157(3):507-26.

35. Polle JEW, Kanakagiri SD, Melis A. tla1, a DNA insertional transformant of the green alga Chlamydomonas reinhardtii with a truncated lightharvesting chlorophyll antenna size. Planta. 2003;217:49-59.

36. Dall'Osto L, Cazzaniga S, Havaux M, Bassi R. Enhanced photoprotection by protein-bound vs free xanthophyll pools: a comparative analysis of chlorophyll b and xanthophyll biosynthesis mutants. Mol Plant. 2010;3(3):576-93.

37. Dall'Osto L, Holt NE, Kaligotla S, Fuciman M, Cazzaniga S, Carbonera D, Frank HA, Alric J, Bassi R. Zeaxanthin protects plant photosynthesis by modulating chlorophyll triplet yield in specific light-harvesting antenna subunits. J Biol Chem. 2012;287(50):41820-34.

38. Havaux M, Dall'Osto L, Bassi R. Zeaxanthin has enhanced antioxidant capacity with respect to all other xanthophylls in Arabidopsis leaves and functions independent of binding to PSII antennae. Plant Physiol. 2007;145:1506-20.

39. Ramel F, Birtic S, Ginies C, Soubigou-Taconnat L, Triantaphylides C, Havaux M. Carotenoid oxidation products are stress signals that mediate gene responses to singlet oxygen in plants. Proc Natl Acad Sci USA. 2012;109(14):5535-40

40. Erickson E, Wakao S, Niyogi KK. Light stress and photoprotection in Chlamydomonas reinhardtii. Plant J. 2015;82(3):449-65.

41. Dall'Osto L, Bassi R, Ruban A. Photoprotective mechanisms: carotenoids. In: Theg SM, Wollman FA, editors. Plastid biology. Springer: New York; 2014. p. 393-435.

42. Peers G, Truong TB, Ostendorf E, Busch A, Elrad D, Grossman AR, Hippler M, Niyogi KK. An ancient light-harvesting protein is critical for the regulation of algal photosynthesis. Nature. 2009;462:518-21.

43. Benzie IF, Strain JJ. The ferric reducing ability of plasma (FRAP) as a measure of "antioxidant power": the FRAP assay. Anal Biochem. 1996;239(1):70-6.

44. Re R, Pellegrini N, Proteggente A, Pannala A, Yang M, Rice-Evans C. Antioxidant activity applying an improved ABTS radical cation decolorization assay. Free Radical Biol Med. 1999;26(9-10):1231-7.

45. Gorman AA, Rodgers MA. Current perspectives of singlet oxygen detection in biological environments. J Photochem Photobiol. 1992;14(3):159-76.

46. Clausen CH, Brooks MD, Li TD, Grob P, Kemalyan G, Nogales E, Niyogi KK, Fletcher DA. Dynamic mechanical responses of Arabidopsis thylakoid membranes during PSII-specific illumination. Biophys J. 2014;106(9):1864-70. 
47. Brooks MD, Sylak-Glassman EJ, Fleming GR, Niyogi KK. A thioredoxin-like/ beta-propeller protein maintains the efficiency of light harvesting in Arabidopsis. Proc Natl Acad Sci USA. 2013;110(29):E2733-40.

48. Malnoe A, Schultink A. The plastid Lipocalin LCNP is required for sustained photoprotective energy dissipation in Arabidopsis. 2018;30(1):196-208.

49. Ledford HK, Chin BL, Niyogi KK. Acclimation to singlet oxygen stress in Chlamydomonas reinhardtii. Eukaryot Cell. 2007;6(6):919-30.

50. Triantaphylides C, Krischke M, Hoeberichts FA, Ksas B, Gresser G, Havaux $M$, Van Breusegem $F$, Mueller MJ. Singlet oxygen is the major reactive oxygen species involved in photooxidative damage to plants. Plant Physiol. 2008;148(2):960-8.

51. Zhang S, Apel K, Kim C. Singlet oxygen-mediated and EXECUTERdependent signalling and acclimation of Arabidopsis thaliana exposed to light stress. Philosophical transactions of the Royal Society of London. Biol Sci. 2014;369(1640):20130227.

52. Camp RG, Przybyla D, Ochsenbein C, Laloi C, Kim C, Danon A, Wagner D, Hideg E, Gobel C, Feussner I, Nater M, Apel K. Rapid induction of distinct stress responses after the release of singlet oxygen in Arabidopsis. Plant Cell. 2003;15(10):2320-32.

53. Kim C, Meskauskiene R, Zhang S, Lee KP, Lakshmanan Ashok M, Blajecka K, Herrfurth C, Feussner I, Apel K. Chloroplasts of Arabidopsis are the source and a primary target of a plant-specific programmed cell death signaling pathway. Plant Cell. 2012;24(7):3026-39.

54. Shao N, Krieger-Liszkay A, Schroda M, Beck CF. A reporter system for the individual detection of hydrogen peroxide and singlet oxygen: its use for the assay of reactive oxygen species produced in vivo. Plant $\mathrm{J}$. 2007;50(3):475-87.

55. Fischer BB, Dayer R, Schwarzenbach $Y$, Lemaire SD, Behra R, Liedtke A, Eggen RI. Function and regulation of the glutathione peroxidase homologous gene GPXH/GPX5 in Chlamydomonas reinhardtii. Plant Mol Biol. 2009;71(6):569-83.

56. Bobik K, Burch-Smith TM. Chloroplast signaling within, between and beyond cells. Front Plant Sci. 2015;6:781.

57. Kleine T, Leister D. Retrograde signaling: organelles go networking. Biochim Biophys Acta. 2016;1857(8):1313-25.

58. Shumbe L, Bott R, Havaux M. Dihydroactinidiolide, a high light-induced beta-carotene derivative that can regulate gene expression and photoacclimation in Arabidopsis. Mol Plant. 2014;7(7):1248-51.

59. D'Alessandro S, Havaux M. Sensing beta-carotene oxidation in photosystem II to master plant stress tolerance. 2019;223(4):1776-83.

60. Garcia-Plazaola Jl, Portillo-Estrada M, Fernandez-Marin B, Kannaste A, Niinemets $U$. Emissions of carotenoid cleavage products upon heat shock and mechanical wounding from a foliose lichen. Environ Exp Bot. 2017;133:87-97.

61. Shumbe L, D'Alessandro S. METHYLENE BLUE SENSITIVITY 1 (MBS1) is required for acclimation of Arabidopsis to singlet oxygen and acts downstream of beta-cyclocitral. Plant Cell Environ. 2017;40(2):216-26.

62. Yilancioglu K, Cokol M, Pastirmaci I, Erman B, Cetiner S. Oxidative stress is a mediator for increased lipid accumulation in a newly isolated Dunaliella salina strain. PLoS ONE. 2014;9(3):e91957.
63. Guarnieri MT, Nag A, Smolinski SL, Darzins A, Seibert M, Pienkos PT. Examination of triacylglycerol biosynthetic pathways via de novo transcriptomic and proteomic analyses in an unsequenced microalga. PLoS ONE. 2011;6(10):e25851.

64. Jacquier N, Choudhary V, Mari M, Toulmay A, Reggiori F, Schneiter R. Lipid droplets are functionally connected to the endoplasmic reticulum in Saccharomyces cerevisiae. J Cell Sci. 2011;124(Pt 14):2424-37.

65. Sun XM, Geng LJ, Ren LJ, Ji XJ, Hao N, Chen KQ, Huang H. Influence of oxygen on the biosynthesis of polyunsaturated fatty acids in microalgae. Bioresour Technol. 2018;250:868-76.

66. Kropat J, Hong-Hermesdorf A, Casero D, Ent P, Castruita M, Pellegrini $M$, Merchant SS, Malasarn D. A revised mineral nutrient supplement increases biomass and growth rate in Chlamydomonas reinhardtii. Plant J. 2011;66(5):770-80.

67. Allen MM, Stanier MY. Growth and division of some unicellular bluegreen algae. J Gen Micro. 1968;51:199-202.

68. Fischer BB, Ledford HK, Wakao S, Huang SG, Casero D, Pellegrini M, Merchant SS, Koller A, Eggen RIL, Niyogi KK. Singlet oxygen resistant 1 links reactive electrophile signaling to singlet oxygen acclimation in Chlamydomonas reinhardtii. Proc Natl Acad Sci USA. 2012;109(20):E1302-11.

69. Gilmore AM, Yamamoto HY. Zeaxanthin formation and energy-dependent fluorescence quenching in pea chloroplasts under artificially mediated linear and cyclic electron transport. Plant Physiol. 1991;96:635-43.

70. Schägger H, von Jagow $G$. Tricine-sodium dodecyl sulfate-polyacrylamide gel electrophoresis for the separation of proteins in the range from 1 to 100 kDa. Anal Biochem. 1987;166:368-79.

71. Towbin H, Staehelin T, Gordon J. Electrophoretic transfer of proteins from polyacrylamide gels to nitrocellulose sheets: procedure and some applications. Proc Natl Acad Sci USA. 1979;76:4350-4.

72. Rappaport F, Beal D, Joliot A, Joliot P. On the advantages of using green light to study fluorescence yield changes in leaves. Biochim Biophys Acta. 2007;1767(1):56-65

73. Maxwell K, Johnson GN. Chlorophyll fluorescence-a practical guide. J Exp Bot. 2000;51:659-68.

74. Havaux M, Eymery F, Porfirova S, Rey P, Dormann P. Vitamin E protects against photoinhibition and photooxidative stress in Arabidopsis thaliana. Plant Cell. 2005;17:3451-69.

75. Baroli I, Gutman BL, Ledford HK, Shin JW, Chin BL, Havaux M, Niyogi KK. Photo-oxidative stress in a xanthophyll-deficient mutant of Chlamydomonas. J Biol Chem. 2004;279(8):6337-44.

76. Axelsson M, Gentili F. A single-step method for rapid extraction of total lipids from green microalgae. PLOS ONE. 2014;9(2):e89643.

77. Horwitz W. Official methods of analysis of AOAC international. Gaithersburg: AOAC International; 2000.

\section{Publisher's Note}

Springer Nature remains neutral with regard to jurisdictional claims in published maps and institutional affiliations.

Ready to submit your research? Choose BMC and benefit from

- fast, convenient online submission

- thorough peer review by experienced researchers in your field

- rapid publication on acceptance

- support for research data, including large and complex data types

- gold Open Access which fosters wider collaboration and increased citations

- maximum visibility for your research: over 100M website views per year

At BMC, research is always in progress.

Learn more biomedcentral.com/submissions 